\title{
The Mechanism of the Depolymerization of Polytetrafluoroethylene With Pyrolytic and Radiolytic Initiation*
}

\author{
Roland E. Florin, Midgett S. Parker ${ }^{1}$ and Leo A. Wall \\ Institute for Materials Research, National Bureau of Standards, Washington, D.C.
}

(December 22, 1965)

\begin{abstract}
The rate of decomposition of polytetrafluoroethylene, exposed to gamma radiation in a flowing helium atmosphere, was studied in the range of temperatures 330 to $450{ }^{\circ} \mathrm{C}$, dose rates 0.1 to 7.6 $\mathrm{MR} / \mathrm{h}$, and sample thicknesses 0.0006 to $0.01 \mathrm{~cm}$. Rate measurements were made with a thermal conductivity cell in the exit stream, which recorded essentially the difference between the thermal and radiation-induced rate, in total molecules of volatiles per second. At temperatures below about $400{ }^{\circ} \mathrm{C}$, the volatile products were a complex mixture. Above $400{ }^{\circ} \mathrm{C}$, tetrafluoroethylene was the major product, and the radiation-induced rate had an activation energy* of 70 to $84 \mathrm{~kJ} / \mathrm{mol}$. The radiation-induced rate is proportional to square root of dose rate, after appropriate allowance for the thermal initiation is made. Analysis of the results suggests that the rate of the thermal initiation has a very high preexponential factor, $10^{28}$ to $10^{30} \mathrm{~s}^{-1}$. The activation energy for termination is large, $\mathrm{E}_{4}>155 \mathrm{~kJ} / \mathrm{mol}$. Diffusion and reverse reaction appear to be minor factors above $400^{\circ} \mathrm{C}$, but a surface reaction may be important. The thermal decomposition mechanism séems clearly to consist of random initiation, termination by bimolecular recombination and a short kinetic chain $\left(13\right.$ at $\left.480{ }^{\circ} \mathrm{C}\right)$.
\end{abstract}

Key Words: Depolymerization, polytetrafluoroethylene, radiolysis, thermal decomposition, mechanisms of degradation, and gamma ray effects.

\section{Introduction}

It appears that the normal pyrolytic reactions of polymers can be much accelerated by the action of ultraviolet light and will then occur at measurable rates below the normal temperatures for pyrolysis. This has been demonstrated for polymethyl methacrylate [1]. ${ }^{2} \quad$ The reason for this effect is that in the set of chain reactions

$$
\begin{aligned}
& \text { Rate } \\
& Q_{n} \stackrel{k_{1}}{\longrightarrow}>R_{i}+R_{n-i} \quad 2 k_{1} n Q_{n} \\
& R_{n} \stackrel{k_{2}}{>}>R_{n-1}+M \quad k_{2} R_{n} \\
& \left\{\begin{array}{c}
R_{n}+Q_{m} \frac{k_{3}}{}>R_{m}^{\prime}+Q_{n} \\
R_{i+j}^{\prime} \frac{k_{3 a}}{}>R_{i}+Q_{j}
\end{array}\right\} \quad k_{3} Q_{m} R_{n} \\
& R_{i}+R_{j} \begin{cases}\frac{k_{4}}{>}>Q_{i+j} & 2 k_{4} R^{2} \\
\underline{k_{4 a}}>Q_{i}+Q_{j} & 2 k_{4 a} R^{2}\end{cases}
\end{aligned}
$$

\footnotetext{
*Research based on work supported by the National Aeronautics and Space Administration.

Present address: IBM Manufacturing Research Division, Endicott, New York.

${ }^{2}$ Figures in brackets indicate the literature references at the end of this paper.
}

for pyrolysis [2, 3, 4], the thermal initiation reaction of high activation energy is replaced by a photoinduced initiation reaction whose rate is proportional to the light intensity $I$ and essentially independent of temperature.

$$
Q_{n} \longrightarrow R_{i}+R_{n-i} \quad 2 \Phi n Q_{n} I .
$$

In the above mechanism for polymer decomposition we have depicted only random initiation in anticipation of the conclusions made in this paper. The symbols are defined as: $Q_{n}$, concentration of polymer molecules with degree of polymerization $n, R_{i}$ concentration of polymer radicals, $M$ monomer, and $\Phi$ a factor including the quantum yield of radicals.

The same result can be anticipated from initiation by $\gamma$-rays and other forms of ionizing radiation. The effect is of some practical importance in limiting the service life of polymers exposed to ionizing radiation at relatively high temperatures, for example, in space applications or nuclear installations. It also can be applied to deduce more detailed information concerning the individual rate constants in pyrolysis, as illustrated by Cowley and Melville [1].

Initiation by gamma radiation is especially convenient in the study of polytetrafluoroethylene, which does not absorb ultraviolet very effectively at convenient wave lengths [5]. 
The kinetics of the thermal decomposition of polytetrafluoroethylene have been reviewed in a recent experimental paper [6]. Investigators are in agreement that in vacuum between 360 and $510{ }^{\circ} \mathrm{C}$, the product is nearly pure monomer and the rate is given rather closely by the eqs [ $7-10]$.

$r_{0}=\frac{1 d C}{(1-C) d t}=\frac{1}{\sum n Q_{n}(0)} \frac{d M}{d t}=4.7 \times 10^{18} e^{-80,500 / R T_{\mathrm{S}}-1},(1)$

where $r_{0}$ is the fractional rate of volatilization of the polymer. The conversion $C$, that is, the fraction of the original sample volatilized, is defined by

$$
C=1-\frac{\sum n Q_{n}(t)}{\sum n Q_{n}(0)} .
$$

In eq (1) and subsequent expressions, $R$ takes the numerical value $1.98646 \mathrm{cal}^{\circ} \mathrm{K}^{-1} \mathrm{~mol}^{-1}$ and $1 \mathrm{cal}$ $=1.4840 \mathrm{~J}$.

The kinetic chain length has been estimated from molecular weight changes [6], but it and other parameters are still subject to large uncertainties.

Recent summaries of the radiation chemistry are available [11-13]. It is noteworthy that two radical species are formed, $-\mathrm{CF}_{2} \cdot$ and $-\mathrm{CF}_{2} \dot{\mathrm{C}} \mathrm{CCF}_{2}-$, and that numerical $G$-values are low, for radical formation and other processes at room temperature [14, 15]. When polytetrafluoroethylene was exposed to radiation at a very high dose rate, the weight loss increased rapidly over a short temperature interval [16].

In the present work the decomposition of polytetrafluoroethylene has been studied in the range of temperatures 330 to $460{ }^{\circ} \mathrm{C}$ and dose rates 0.1 to 7.66 megaroentgens per hour $(\mathrm{MR} / \mathrm{h})$, and expressions have been deduced for the thermal initiation rate, the chain length under various circumstances, and the activation energies of elementary rate processes. Rate of monomer evolution was measured by changes in thermal conductivity of a flowing stream of helium.

\section{Experimental Procedure}

\subsection{Apparatus}

The polymer samples were usually polytetrafluoroethylene cast film, of thicknesses 0.0062, 0.0025, and $0.01 \mathrm{~cm}$. In certain studies related to molecular weight, powdered samples were used, of molecular weights 1 to $2.5 \times 10^{5}, 1$ to $3 \times 10^{6}$, and $1 \times 10^{7}$, estimated by the standard specific gravity method of Sperati and Starkweather [12].

Tetrafluoroethylene for calibration was prepared by low-pressure pyrolysis of the polymer [17]. Helium was the commercial gas of 99.99 percent assay. Mass spectrometer analysis indicated no appreciable impurities, and specifically less than 0.07 percent of $\mathrm{H}_{2}$.
Attempts to concentrate $\mathrm{CO}_{2}$ by trapping out from the stream at $77^{\circ} \mathrm{K}$ led to inconsistent results, from less than 0.002 to 0.01 percent.

Helium was led from a cylinder through one side of a thermal conductivity cell, thence to a pyrolysis chamber containing the sample in the radiation source, and finally to the other side of the thermal conductivity cell and to a trap immersed in liquid nitrogen. The principle of the method has been applied before [18]. The pyrolysis chamber was constructed of stainless steel, in two pieces, joined at the top by a flange and an O-ring. The outer wall was $40 \mathrm{~cm}$ in length by $5 \mathrm{~cm}$ diam. The top member contained an extension, $35 \mathrm{~cm}$ length by $4.5 \mathrm{~cm}$ diam, which projected downward inside the chamber space, and carried at its lower end a helium inlet tube and a detachable, perforated hollow stalk bearing four aluminum trays $4.5 \mathrm{~cm}$ in diameter and $0.6 \mathrm{~cm}$ apart, upon which circular sheets of the sample were laid. An internal thermocouple was mounted near the middle of the stalk; its leads were brought out through the helium inlet tube and a picein seal. The helium outlet tube was connected to the top flange. A controlled furnace was wound about the outer wall covering the lower 15 $\mathrm{cm}$ of its length and extending $4 \mathrm{~cm}$ below the bottom. A control thermocouple was mounted in the furnace insulation. The furnace assembly was mounted in a cylindrical can at the end of a long tube which carried the electrical leads and the helium connections and served as a handle. Helium going from the tank to the furnace and from the furnace to the detector passed through $4 \mathrm{~m}$ of plastic tubing and $4.5 \mathrm{~m}$ of copper tubing in each line. The copper tubing was mounted in a thermostatted cabinet containing the detector. Helium flow and pressure were monitored by two flow meters and a manometer. Each side of the thermal conductivity cell contained a pair of tungsten filaments, in series, with a resistance of about $100 \Omega$, in each arm of the bridge. The bridge current was $250 \mathrm{~mA}$, well above the recommended level, for increased sensitivity. Bridge unbalance was fed to a recorder. In the absence of the cabinet and copper heat exchange coils, the output of the bridge suffered considerable drift and a fluctuation of a large fraction of $1 \mathrm{mV}$, correlated with changes of room temperature. These fluctuations were reduced about 10 -fold by the heat exchange coils and by controlling the room temperature to within $0.2{ }^{\circ} \mathrm{C}$ by a sensitive room thermostat.

Measurements were made by bringing the sample to temperature in the furnace at a chosen helium flow rate in a region of negligible radiation dose rate, establishing a recorder base line at this temperature, then placing the furnace in a position of known dose rate. A typical recorder curve is shown in figure 1. From the theory of vapor chromatography instrumentation [19], the height of the response will be nearly proportional to the mole fraction of nonhelium components in the gas passing the detector, minus the mole fraction of such components, if any, under base-line conditions. The shape of the experimental curve is roughly what is to be expected of a flow chamber with thorough mixing, in which product formation 
at a constant rate begins and ceases sharply after the starting and cutoff times [20]. There is an additional delay, as shown in figure 1 , for the time of travel through the tubing system. Most of the experiments were done at a helium flow rate of $0.217 \mathrm{~cm}^{3} / \mathrm{s}$, which involved a time delay of the order of 15 to 20 min to reach maximum response. This time delay obscures any short-lived transient phenomena in the kinetics of the decomposition. The weight loss was usually held to less than 20 percent during a series of experiments with a given sample. The apparatus was calibrated by bleeding pure tetrafluoroethylene into the helium line to the furnace, from a $30-\mathrm{ml}$ bulb in which the pressure (1.1 to $2.0 \mathrm{~atm}$ ) was accurately measured as a function of time by a mercury column and cathetometer. At low feed rates, precision was impaired by fluctuations of barometric pressure. Measurements at various flow rates are consistent with a sensitivity of $0.03 \mathrm{~mol}$ percent $\mathrm{C}_{2} \mathrm{~F}_{4}$ per millivolt. The response was not noticeably influenced by variations of furnace temperature from 20 to $400{ }^{\circ} \mathrm{C}$, nor by the presence or absence of radiation. It would presumably be the same within errors of measurement for most other gases of reasonably low thermal conductivity. A few attempts were made to measure changes with temperature of the purely thermal rate of decomposition by establishing a preliminary base line at about $250^{\circ} \mathrm{C}$. The results were in fair agreement with the thermal decomposition rates in the literature if a correction of about $+27{ }^{\circ} \mathrm{C}$ is applied to the internal thermocouple reading, see table 1 . However, factors other than the thermal decomposition rate could have contributed to the response of the instrument to changes of temperature, and it is probable that only rate differences at constant temperature are reliably detected.

TABLE 1. Detector responses in the absence of radiation

\begin{tabular}{l|c|c|c|c|c}
\hline \hline & 290 & 315.5 & 356.5 & 403.4 & 437.9 \\
Temp., ${ }^{\circ} \mathrm{C}$ a & 0 & 0.08, & 0.24 & 0.88 & 2.33 \\
Response, $\mathrm{mV}$ & 0 & .24 & 1.6 & 7.2 & 19.0 \\
Equivalent rate, $\mathrm{s}^{-1 \cdot} \times 10^{7 \mathrm{~b}}$ & $<$ & 1.9 & 1.9 & & \\
Thermal rate, $\times 10^{7 \mathrm{c}}$ & $<0.001$ & $<0.001$ & 0.002 & 0.52 & 11.0 \\
\hline
\end{tabular}

a Corrected, see "Experimental Procedure."

" $0.0025 \mathrm{~cm}$ thickness, $0.35 \mathrm{~g}$.

"Data of Madorsky, ref. 7 .

The losses in weight measured after fixed long periods of time in the absence of radiation could be correlated with the thermal weight loss data of Madorsky [7] only if a correction of $+27^{\circ} \mathrm{C}$ was applied to the interior thermocouple temperature. The data of Madorsky on polytetrafluoroethylene appear to be nearly free from the usually encountered uncertainties of temperature in pyrolysis experiments. Since it was desired to correlate our results with these data, a temperature correction of $+27^{\circ} \mathrm{C}$ has been applied to all data except the temperature scale of figure 1 . A nearly constant correction of this magnitude is not unreasonable for apparatus of the present shape, in which radiant heat transfer predominates [8].

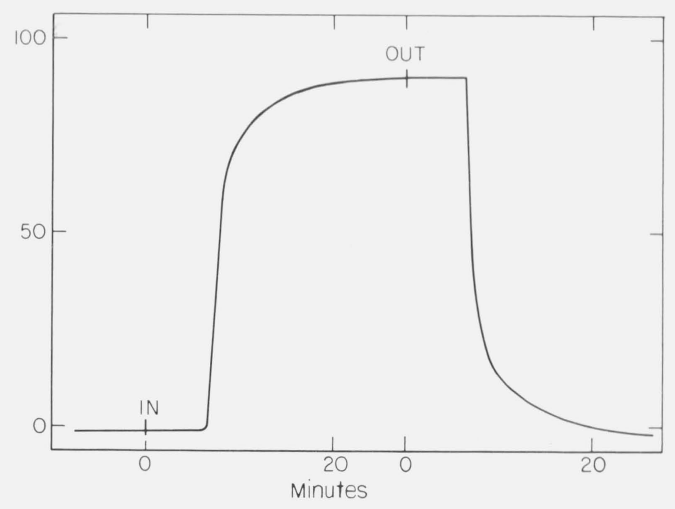

FiguRE 1. Experimental detector response as a function of time. Time sample is placed in and taken out of $\gamma$-ray source is indicated.

\subsection{Dosimetry}

Dose rates were measured by cobalt glass dosimeters placed inside the furnace and exposed for measured times at several fixed sites. The ultimate calibration was referred to the Fricke ferrous sulfate dosimeter. The sources were a nominal 2000-Ci (curie) $\mathrm{Co}^{60}$ source and a $10,000-\mathrm{Ci}$ source consisting of a cylindrical assembly of vertical pencil-shaped capsules, in a pool of water. Dose rates from somewhat idealized sources of this geometry are described mathematically in the literature [21]. At relatively small distances outside the source there appears to be little deviation from an inverse square relationship. Accordingly, the dose rate measurements were correlated by a plot of $\log \left(I X^{2}\right)$ against $X_{w}$, where $I$ is the dose rate, $X$ the distance from the center of the source, and $X_{w}$ that part of the distance occupied by water. Such plots were nearly linear, with some downward curvature. The smooth-curve values were chosen as the dose rate at the given position.

Despite the considerable variation of distance within a circular sample, outside the source, the dose rate at its center can be shown to give good approximation to the dose rate averaged over sample area, and an excellent approximation if the square root of dose rate is averaged.

To estimate dose rate within the $10,000-\mathrm{Ci}$ source, dosimeters were exposed at a variety of locations within the apparatus, and correlated with the aid of functions given in the literature [21], to obtain an average over the total sample. The measured values inside the source were about 20 percent lower than would be predicted from the values outside the source with the given mathematical description. The error may be in the dosimetry, as rather short exposure times were necessary, with large relative errors. Although the precision of individual measurements was never better than 5 percent, the relative values from the smoothed curve are presumably better.

The factor $0.526 \times 10^{20} \mathrm{eV} / \mathrm{g}$ MR, derived from interpolated atomic absorption factors [22], was used to convert megaroentgens to $\mathrm{eV} / \mathrm{g}$ in polytetrafluoroethylene. 
Because the samples were quite thin, the dose rates in them may be subject to systematic errors associated with secondary electron equilibrium [22, 22a]. These errors may be nearly constant in a series of samples of the same thickness, but may vary with thickness. Considering the dimensions and materials, and neglecting the thickness of the helium atmosphere, 0.0002 to $0.0008 \mathrm{~g} / \mathrm{cm}^{3}$, the received dose will be higher than that computed from atomic absorption factors, and will be highest in the thinnest samples.

\subsection{Product Analysis}

In a number of instances the gases produced by the decomposition were collected in liquid nitrogen traps and analyzed by mass spectrometry and by vapor chromatography in a $60-\mathrm{cm}$ column of silicone grease on Chromosorb at $-80^{\circ} \mathrm{C}$.

A large excess of carbon dioxide was usually found, which was greatly reduced but not eliminated by the provision of a liquid nitrogen guard trap following the collection trap. The weight increase in the collection trap usually exceeded the weight loss of the polymer, presumably because of backward diffusion of atmospheric water and carbon dioxide. The chromatographic method employed produced relatively poor resolution: $\mathrm{C}_{2} \mathrm{~F}_{4}$ was separated almost completely from $\mathrm{CO}_{2}$ but not from air or $\mathrm{CF}_{4}: \mathrm{C}_{3} \mathrm{~F}_{6}$ coincided with $\mathrm{CO}_{2}$ : and the complex mixture from atmospheric pressure pyrolysis of Teflon [17] yielded five distinct but not totally resolved peaks.

Used polymer samples were adherent to the trays and apparently uniform in thickness. This was checked in a few instances by measuring the thickness of residue plus supporting tray with a micrometer thickness gage. The used film was discolored to a medium brownish gray, with nearly black lines extending outward from the helium flow orifices.

\subsection{Chlorine Fixation}

The radiation-induced fixation of chlorine was also measured by exposing sample tubes containing about $1 \mathrm{~g}$ polytetrafluoroethylene film and $30 \mathrm{~cm}^{3}$ chlorine gas at 200 torr (measured at $25{ }^{\circ} \mathrm{C}$ ), in a furnace at a dose rate of $7.6 \mathrm{MR} / \mathrm{h}$, to a total dose of 20 to $30 \mathrm{MR}$. A large excess of chlorine remained. The product was then heated for $2 \mathrm{~h}$ at $270{ }^{\circ} \mathrm{C}$ under vacuum to remove volatile chlorine compounds, the resultant weight loss being a few percent, and the residue was analyzed for chlorine.

\section{Results}

\subsection{Rate of Reaction}

In general summary, the radiation-produced increments in gas evolution were small absolutely, always a fraction of the total weight loss, and exhibited a low temperature coefficient. In the volatile products, the monomer $\mathrm{C}_{2} \mathrm{~F}_{4}$ was a principal component at the higher temperatures investigated, but rarely the only component.
The results of the rate experiments are shown in figure 2 as logarithmic plots of the rate-difference due to radiation, $r-r_{0}, \mathrm{~s}^{-1}$, versus the reciprocal of absolute temperature, for each of several dose rates and sample thicknesses. It is evident that these values are all rather low, and that their temperature coefficient is small. Supplementary results outside the range of the figure, and usually of lower precision, are listed in table 2. Since the detector response goes approximately as the number of moles of gas regardless of identity, the correct units for $r-r_{0}$ may be regarded as

$$
\frac{\text { moles total gas }}{\text { (base mole polymer) (sec) }} \text {. }
$$

TABLE 2. Radiation-induced decomposition of polytetrafluoroethylene; supplement to figure $2^{\text {" }}$

\begin{tabular}{l|c|c|c|c|c|c}
\hline \hline & & & & & \\
Temp ${ }^{\circ} \mathrm{C}^{b}$ & 354.6 & 417.0 & 369.9 & 386.6 & 401.2 & 405.2 \\
Dose rate, MR/h & 0.22 & 0.22 & 7.66 & 7.66 & 7.66 & 7.66 \\
$\begin{array}{c}\text { Rate, } r-r_{0}, \\
\mathrm{~s}^{-1} \times 10^{7}\end{array}$ & 2.9 & 3.4 & 19 & 19 & 20 & 15 \\
\hline
\end{tabular}

a Thickness of film, $0.0025 \mathrm{~cm}$.

"Corrected, see "Experimental Procedure."

The method of operation made it possible to obtain with fair precision only the difference between the actual rate $r$ and the thermal rate in the absence of radiation, $r_{0}$. Under the most favorable conditions recorder fluctuations seldom exceeded $\pm 0.03 \mathrm{mV}$ for periods of $1 \mathrm{~h}$. At the flow rate most used, this is equivalent to $0.03 \times \frac{2.82}{w} \times 10^{-7} \mathrm{~mol} /($ base $\mathrm{mol}$ )

where $w$ is the sample mass in grams. The resultant uncertainty is about $0.24 \times 10^{-7} \mathrm{~s}^{-1} \mathrm{f}_{\mathrm{Gr}}$ the samples $0.0025 \mathrm{~cm}$ thick (mass $0.33 \mathrm{~g}$ ), about $1 \times 10^{-7} \mathrm{~s}^{-1}$ for the $0.00062-\mathrm{cm}$ samples, and $0.06 \times 10^{-7} \mathrm{~s}^{-1}$ for the 0.01 $\mathrm{cm}$ samples. For less favorable periods these estimates should be multiplied three-fold to allow for occasional unexplained drifts. An additional error of 5 to 10 percent of the reported value may be expected for experiments not near the beginning or end of a sequence, where the weight of the sample at the time of the experiment was uncertain. The curves of figure 2 would be activation energy plots for the $\gamma$-ray induced reaction if the thermal rate $r_{0}$ were negligible and the product composition constant over the temperature interval. Since these conditions did not usually prevail, the curves constitute merely a device for displaying and interpolating results. Figures 3 and 4 illustrate the variation of rate difference with dose rate in a carefully controlled sequence of experiments on $0.0025-\mathrm{cm}$ film at $402.5{ }^{\circ} \mathrm{C}$. It is evident that the rate-difference, $r-r_{0}$, is not linear in either dose rate $I$ or square root of dose rate. This appears to be generally true for the $0.0025-\mathrm{cm}$ and 0.01 $\mathrm{cm}$ films at all temperatures, as far as the much more limited data go, but not for the $0.0006-\mathrm{cm}$ films, for which the variation seems nearly linear in dose rate, table 3. In this table, reduction to constant temperature has not been attempted; by reference to figure 2 , the corrections cannot be much greater than the experimental error. 


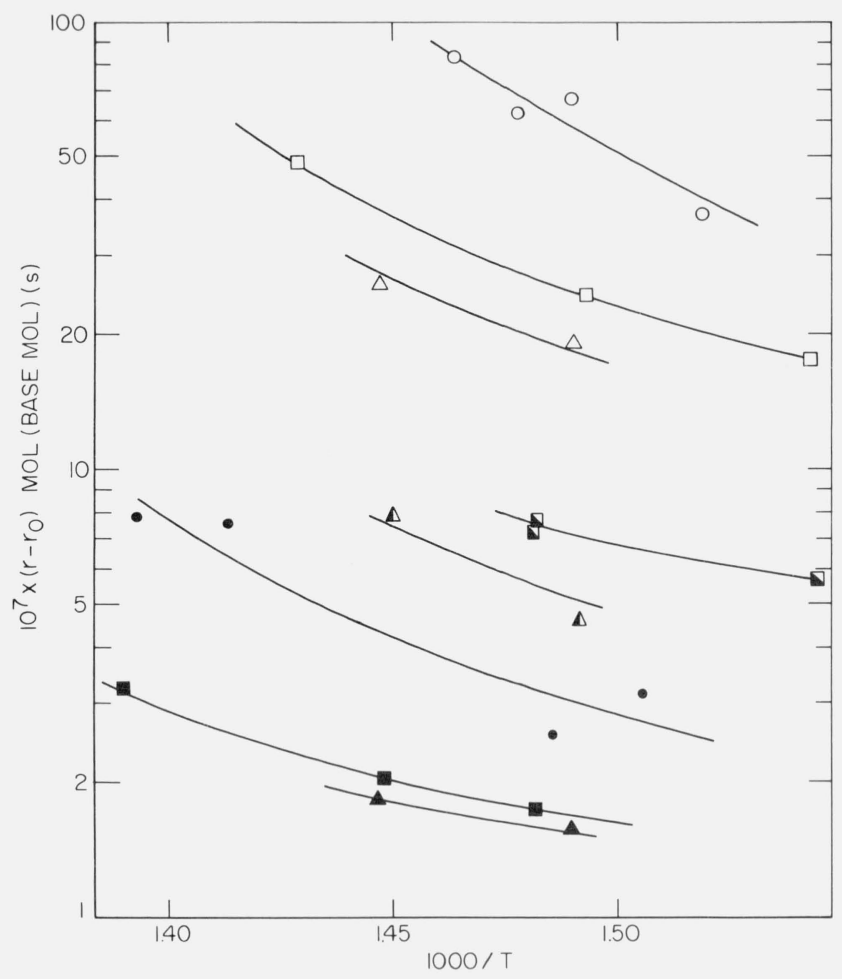

FIGURE 2. Increments in gas evolution rate produced by radiation, $\mathrm{r}-\mathrm{r}_{0}$, as a function of temperature, dose rate and film thickness.

O $7.66 \mathrm{MR} / \mathrm{h}, 0.0006 \mathrm{~cm}$ $7.66 \mathrm{MR} / \mathrm{h}, 0.0025 \mathrm{~cm}$

$7.66 \mathrm{MR} / \mathrm{h}, 0.01 \mathrm{~cm}$

$1.39 \mathrm{MR} / \mathrm{h}, 0.0025 \mathrm{~cm}$

$1.39 \mathrm{MR} / \mathrm{h}, 0.01 \mathrm{~cm}$

$0.22 \mathrm{MR} / \mathrm{h} .0 .0006 \mathrm{~cm}$

$0.22 \mathrm{MR} / \mathrm{h}, 0.0025 \mathrm{~cm}$

$0.22 \mathrm{MR} / \mathrm{h}, 0.01 \mathrm{~cm}$

TABLE 3. Evolution of volatiles from $0.0006 \mathrm{~cm}$ film of polytetrafluoroethylene as a function of dose rate

\begin{tabular}{l|c|c|c|c|c|c}
\hline \hline & & & & & & \\
Temp, ${ }^{\circ} \mathrm{C}$ a & 424.2 & 427.0 & 425.2 & 425.2 & 432 & 4.37 \\
Dose rate, MR/h & 0.144 & 0.22 & 0.337 & 0.644 & 2.2 & 7.66 \\
$r-r_{0}, \mathrm{~s}^{-1}, \times 10^{7}$ & 1.6 & 2.5 & 3.9 & 5.3 & 12.9 & 88 \\
$\left(r-r_{0}\right) / I, \times 10^{7}$ & 11 & 11 & 11 & 8 & 6 & 11 \\
\hline
\end{tabular}

a Corrected, see "Experimental Procedure."

The thinnest samples are also exceptional with respect to $r-r_{0}$ considered as a function of sample thickness, figure 6 .
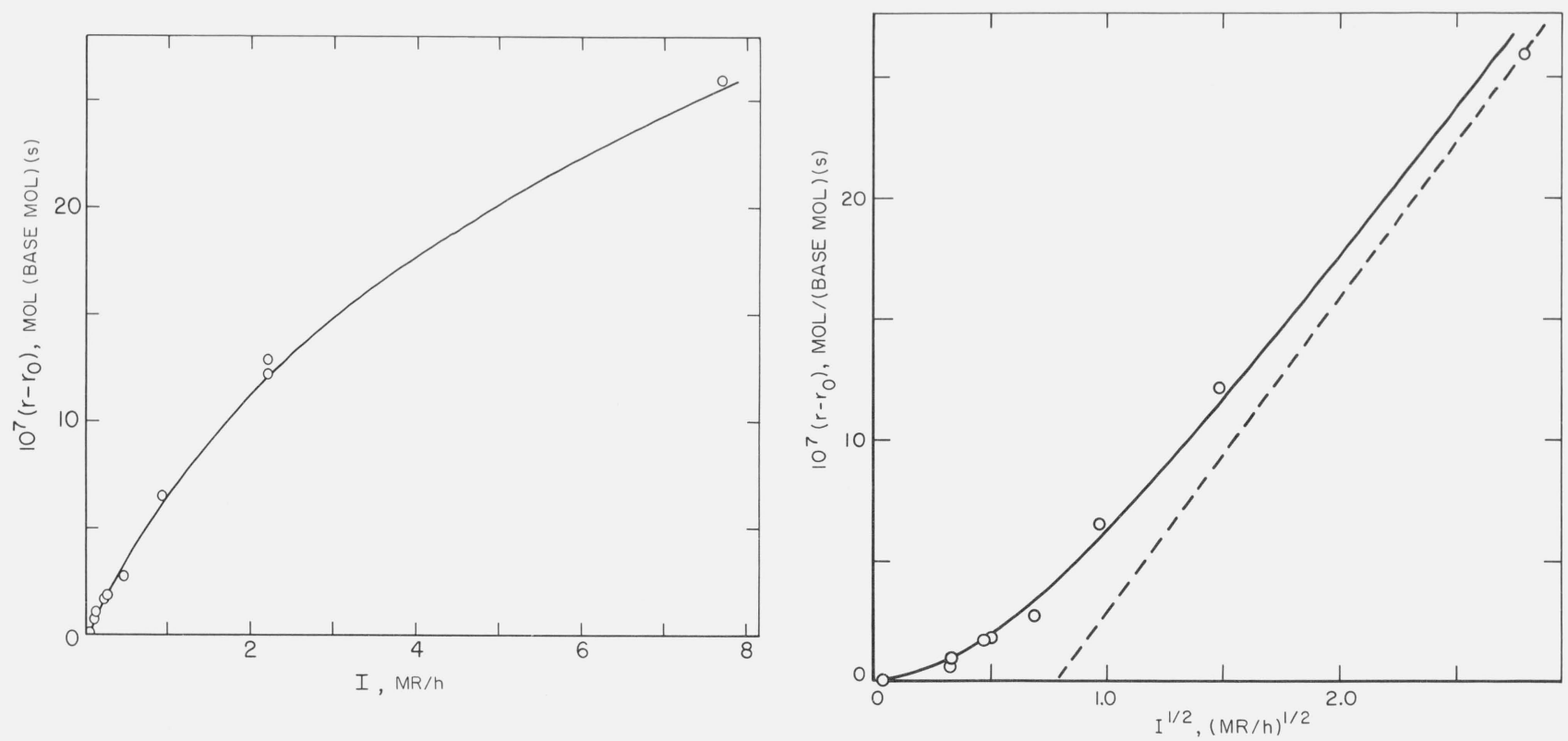

FIGURE 4. Radiation increments in gas evolution rate from polytetrafluoroethylene, $\mathrm{r}-\mathrm{r}_{0}$, as a function of square root of dose rate. Corrected temperature $429.5{ }^{\circ} \mathrm{C}$ : film thickness $0.0025 \mathrm{~cm}$. Theoretical hyperbola and asymptote, using parameters from figure 5. Equation of hyperbola is

$$
\frac{\left(r-r_{0}+10.37 \times 10^{-7}\right)^{2}}{\left(10.37 \times 10^{-7}\right)^{2}}-\frac{\left(l^{1 / 2}\right)^{2}}{(0.792)^{2}}=1 .
$$


TABLE 4. Weight loss and gas evolution rates ${ }^{\text {a }}$

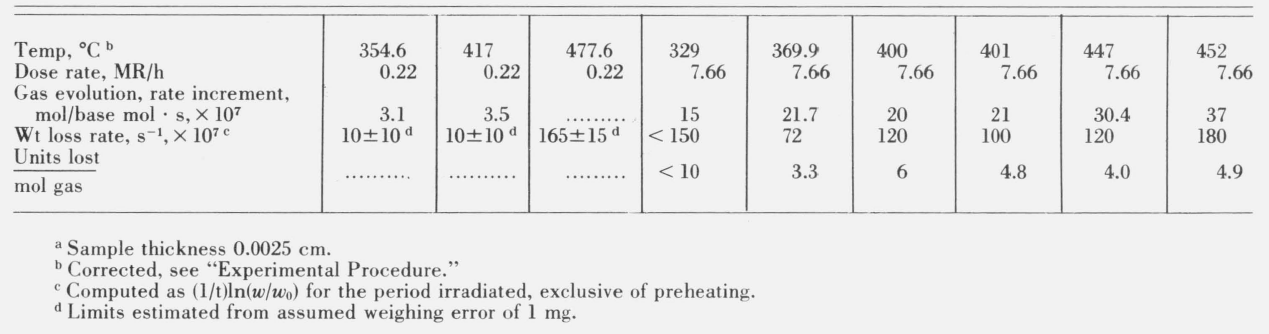

In table 4 the weight losses are compared with the rate-increment of gaseous product formation under various conditions. The weight loss is always several times the rate-increment measured by gaseous products. At the higher temperatures such large discrepancies can of course be explained by the existence of an appreciable thermal rate. At the lowest temperatures, the thermal rate is negligible and other factors are important. For example at $369.9{ }^{\circ} \mathrm{C}$ (corrected) and $7.66 \mathrm{MR} / \mathrm{h}$ the gaseous product rate increment was $21.7 \times 10^{-7} \mathrm{~s}^{-1}$, the observed weight loss rate $72 \times 10^{-7} \mathrm{~s}^{-1}$ and the thermal weight loss rate, from the literature [7], should be $2 \times 10^{-9} \mathrm{~s}^{-1}$. Hence, the large ratio of weight loss to gas molecule production at this temperature must depend entirely upon the predominance in the product of unknown molecules much larger than monomer.

\subsection{Products of Reaction}

The mass spectra of collected volatile products were very complex, with mass peaks as high as $300\left(\mathrm{C}_{6} \mathrm{~F}_{12}^{+}\right)$, and defeated any attempts at full analysis. They also showed the presence of much carbon dioxide, 3 to 10 times as much as the maximum possible fraction of $\mathrm{C}_{2} \mathrm{~F}_{4}$. Silicon tetrafluoride was absent except for a trace on one occasion. A large sample collected at $477.6^{\circ} \mathrm{C}$ (corrected) and $0.22 \mathrm{MR} / \mathrm{h}$ was exceptional, consisting of $\mathrm{C}_{2} \mathrm{~F}_{4}$ and 0.3 percent $\mathrm{C}_{3} \mathrm{~F}_{6}$.

The large amount of $\mathrm{CO}_{2}$ was probably a result of the trapping arrangements. This is supported by observations that the weight collected usually exceeded the polymer weight loss, and that the proportion of $\mathrm{CO}_{2}$, was less in experiments with a second guard trap.

Other sources for some of the $\mathrm{CO}_{2}$ require consideration. The analysis of the helium does not exclude $10^{-5}$ parts of $\mathrm{O}_{2}$, and more could have diffused in through the 3 to $4 \mathrm{~m}$ of flexible tubing in the helium inlet line. From the quoted permeability of plasticized polyvinyl chloride [23] to oxygen, stated as 50 to 305 $\left(\mathrm{cm}^{3}\right)(\mathrm{mol}) /\left(100 \mathrm{in}^{2}\right)(24 \mathrm{~h})$ and the measured length $(4 \mathrm{~m})$, diameter $(0.75 \mathrm{~cm})$, and wall thickness $(0.19 \mathrm{~cm})$, an amount equal to 1 to $10 \times 10^{-10} \mathrm{~mol} / \mathrm{s}^{-1}$ could have entered by diffusion, which if it reacts stoichiometrically, is equivalent to a rate of 0.3 to $3 \times 10^{-7} \mathrm{~s}^{-1}$ in a $0.33 \mathrm{~g}$ sample. Golden [24] has reported and discussed a reaction of polytetrafluoroethylene with oxygen, forming $\mathrm{COF}_{2}$ as a primary product, which can subsequently yield $\mathrm{CO}_{2}$ and $\mathrm{SiF}_{4}$ by reaction with glass or water. The failure to find $\mathrm{SiF}_{4}$, as well as the low pressure at which any oxygen would be present, makes it unlikely that these reactions were important here. Possibly $\mathrm{COF}_{2}$ could have been formed and reacted in the plastic part of the exit tube with small amounts of hydroxylic compounds or water, the resultant $\mathrm{HF}$ being totally absorbed in the plastic. It is assumed for the present that all the $\mathrm{CO}_{2}$ found was of extraneous origin.

Another possible product from oxygen is the oxide $\mathrm{CF}_{2} \mathrm{CF}_{2} \mathrm{O}$, recently reported from the radiationinduced reaction of $\mathrm{C}_{2} \mathrm{~F}_{4}$ and $\mathrm{O}_{2}$ [25]; however, no trace of the corresponding fragment ions was found in mass spectra.

A few tentative conclusions may be drawn by considering the largest peaks of some of the mass spectra, table 5 , in the light of the known cracking patterns of fluorocarbons [26]. The most important omissions in available cracking patterns are probably hexafluorocyclopropane, octafluorobutene- 2 and the higher perfluoroolefins. The $\mathrm{C}_{2} \mathrm{~F}_{3}$ peak is major for $\mathrm{C}_{2} \mathrm{~F}_{4}$ and much smaller for other known fluorocarbons, the $\mathrm{C}_{n} \mathrm{~F}_{2 n-1}$ and $\mathrm{C}_{n} \mathrm{~F}_{2 n}$ peaks are large for a perfluoroolefin $\mathrm{C}_{n} \mathrm{~F}_{2 n}$, and the $\mathrm{CF}_{3}$ peak is major in perfluoroparaffins and less important in perfluoroolefins.

Unless hexafluorocyclopropane and octafluorobutene-2 are present in large amounts and have large $\mathrm{C}_{2} \mathrm{~F}_{3}$ sensitivities, the amount of $\mathrm{C}_{2} \mathrm{~F}_{4}$ is probably not much lower than that computed from the sensitivity of $\mathrm{C}_{2} \mathrm{~F}_{4}$ at this peak. The $\mathrm{CF}_{3}$ peak height is

TABLE 5. Relative intensities of mass spectra of volatiles produced from polytetrafluoroethylene $(0.33 \mathrm{~g})$ irradiated at the indicated temperatures ${ }^{\text {a }}$ with $7.66 \mathrm{MR} / \mathrm{h}$

\begin{tabular}{l|r|r|r}
\hline & \multicolumn{3}{|c}{ Relative Intensities at } \\
\cline { 2 - 4 } $\mathrm{m} / \mathrm{e}$, ion & & \multicolumn{3}{|c}{} \\
& & & \multicolumn{3}{c}{${ }^{\circ} \mathrm{C}$} & $407{ }^{\circ} \mathrm{C}$ & $462{ }^{\circ} \mathrm{C}$ \\
& & & \\
& & & \\
$31 \mathrm{CF}$ & 1,550 & 300 & 390 \\
$44 \mathrm{CO}_{2}$ & $>10,000$ & 2,190 & 2,610 \\
$50 \mathrm{CF}_{2}$ & 570 & 70 s & 177 \\
$69 \mathrm{CF}_{3}$ & 2,310 & 234 & 198 \\
$81 \mathrm{C}_{2} \mathrm{~F}_{3}$ & 880 & 105 & 250 \\
$93 \mathrm{C}_{3} \mathrm{~F}_{3}$ & 132 & 45 & 36 \\
$100 \mathrm{C}_{2} \mathrm{~F}_{4}$ & 775 & 84 & 189 \\
$119 \mathrm{C}_{2} \mathrm{~F}_{5}$ & 280 & 29 & 22 \\
$131 \mathrm{C}_{3} \mathrm{~F}_{5}$ & 3,130 & 258 & 197 \\
$150 \mathrm{C}_{3} \mathrm{~F}_{6}$ & 184 & 13 & 14 \\
$181 \mathrm{C}_{4} \mathrm{~F}_{7}$ & 520 & 558 & 66 \\
$200 \mathrm{C}_{4} \mathrm{~F}_{8}$ & 126 & 7 & 7 \\
$231 \mathrm{C}_{5} \mathrm{~F}_{9}$ & 98 & & \\
$250 \mathrm{C}_{5} \mathrm{~F}_{10}$ & 21 & & \\
$281 \mathrm{C}_{6} \mathrm{~F}_{11}$ & 33 & & \\
$300 \mathrm{C}_{6} \mathrm{~F}_{12}$ & 5 & & \\
\hline
\end{tabular}


too small to accommodate any large proportion of perfluoroparaffins. Provisional constructions based on $\mathrm{C}_{2}, \mathrm{C}_{3}$, and $\mathrm{C}_{4}$ olefins and perfluorocyclobutane are roughly compatible with the analyses suggested in table 6 .

TABLE 6. Decomposition products

\begin{tabular}{|c|c|c|c|c|c|}
\hline \multirow{2}{*}{$\begin{array}{l}\text { Tempera- } \\
\text { ture }{ }^{\circ} \mathrm{C} \text { a }\end{array}$} & \multicolumn{5}{|c|}{ Mole percent in non- $\mathrm{CO}_{2}$ portion } \\
\hline & $\mathrm{C}_{2} \mathrm{~F}_{4}$ & $\mathrm{C}_{3} \mathrm{~F}_{6}$ & $i-\mathrm{C}_{4} \mathrm{~F}_{8}$ & $1-\mathrm{C}_{4} \mathrm{~F}_{8}$ & $c y-\mathrm{C}_{4} \mathrm{~F}_{8}$ \\
\hline $\begin{array}{l}407^{\mathrm{b}} \\
462^{\mathrm{b}} \\
487^{\mathrm{c}}\end{array}$ & $\begin{array}{l}40 \\
63 \\
97\end{array}$ & $\begin{array}{r}13 \\
9 \\
3\end{array}$ & $\begin{array}{l}18 \\
13\end{array}$ & $\begin{array}{l}28 \\
11\end{array}$ & $\begin{array}{l}1 \\
3\end{array}$ \\
\hline
\end{tabular}

Vapor chromatography was complicated by the large amounts of $\mathrm{CO}_{2}$, which was not removed chemically. The overlap of $\mathrm{CO}_{2}$ and $\mathrm{C}_{3} \mathrm{~F}_{6}$ is almost complete, and because of the long tail region of $\mathrm{CO}_{2}$ and great breadth of higher component peaks one can only say that no higher olefin amounted to as much as 10 percent of the $\mathrm{CO}_{2}$, i.e., 100 percent of the $\mathrm{C}_{2} \mathrm{~F}_{4}$. A clear separation of $\mathrm{C}_{2} \mathrm{~F}_{4}$ and $\mathrm{CO}_{2}$ was effected; however, any $\mathrm{CF}_{4}$ would appear with $\mathrm{C}_{2} \mathrm{~F}_{4}$. Air, which could also interfere, was removed by degassing at $77^{\circ} \mathrm{K}$. The principal utility of the chromatograms was to demonstrate that $\mathrm{C}_{2} \mathrm{~F}_{4}$ was indeed present, and that its ratio to $\mathrm{CO}_{2}$ was about that estimated from mass spectra.

The product composition showed no clear trend with dose rate or radiation history up to $100 \mathrm{MR}$, although such trends should exist. The only persistent correlation was with temperature; the mass spectral data suggest, for the non- $\mathrm{CO}_{2}$ portion, about 40 percent $\mathrm{C}_{2} \mathrm{~F}_{4}$ at $407{ }^{\circ} \mathrm{C}, 60$ percent $\mathrm{C}_{2} \mathrm{~F}_{4}$ at $462{ }^{\circ} \mathrm{C}$, and nearly 100 percent $\mathrm{C}_{2} \mathrm{~F}_{4}$ at $487^{\circ} \mathrm{C}$.

The product compositions and their trend with temperature introduce errors of the order of 50 percent into the rate data. Corrections for this appear futile, in view of the inexactness of the composition results, the slowness of the trend with temperature, and especially the lack of any demonstrable variation with dose rate. At temperatures below the range of figure 2 , the complexity is too great for kinetic treatment. It is curious that despite this complexity, no waxlike deposits of high-molecular-weight products were ever found in the cooler regions of the decomposition chamber.

\subsection{Chlorine Fixation}

The $G$-value computed from fixation of chlorine in the polymer by radiation was $3.0 \pm 0.1$ atoms of chlorine fixed per $100 \mathrm{eV}$ absorbed, at temperatures of 327,340 , and $380{ }^{\circ} \mathrm{C}$. A thermal chlorination blank at $327{ }^{\circ} \mathrm{C}$ was negligible. The polymer strips were unchanged in appearance in the thermal blank, but melted in the radiation experiments. The $G$-value for chlorine absorption may be somewhere near that for creation of radicals escaping the primary cage.

\section{Discussion}

\subsection{Kinetics}

Assuming random initiation and moderate zip length and permitting monomer only to evaporate, one can derive the following rate expression for the process of decomposition

$$
\frac{d M}{d t}=k_{2} R_{T}
$$

where $d M / d t$ is the moles of monomer evaporated per second from a sample containing $R_{T}$ moles of polymer radicals. Since this is an open system and the sample volume, which is decreasing, is proportional to weight, the formulation depends to some extent on the concentration units used in bimolecular steps. For our purpose we choose $R$ as moles of radicals per $\mathrm{cm}^{3}$. Then the steady condition is written

$$
k_{1} \sum n Q_{n}=k_{4} R^{2}
$$

where $Q_{n}$ is now moles of polymer molecules per $\mathrm{cm}^{3}$. The $\sum n Q_{n}$ is simply $\rho / m$ where $\rho$ is the density and $m$ the monomer molecular weight. The radical concentration is then

$$
R=\left(\frac{k_{1}}{k_{4}} \frac{\rho}{m}\right)^{1 / 2}
$$

and

$$
\frac{d M}{d t}=k_{2} R V=k_{2} R \frac{W}{\rho}=k_{2} R \frac{m \sum n Q_{n}(t)}{\rho} .
$$

Since

$$
\begin{gathered}
\sum n Q_{n}(t)=[1-C] \sum n Q_{n}(0), \\
r_{0}=(1-C) \frac{d C}{d t}=\frac{1}{(1-C) \sum n Q_{n}(0)} \frac{d M}{d t}=k_{2}\left(\frac{k_{1}}{k_{4}} \frac{m}{\rho}\right)^{1 / 2} \mathrm{~s}^{-1} .
\end{gathered}
$$

If conditions are such that initiation does not occur thermally but is induced photochemically or by ionizing radiation, and if the character of all species involved is unchanged, then the steady state condition, eq (4) is replaced by

$$
\Phi I \quad \sum n Q_{n}=k_{4} \mathrm{R}^{2}
$$

where $I$ is the intensity of radiation.

The resulting rate becomes

$$
r_{\gamma}=k_{2}\left(\frac{\Phi}{k_{4}} \frac{m}{\rho}\right)^{1 / 2} I^{1 / 2} \mathrm{~s}^{-1} .
$$


The ratio $r_{\gamma} I^{-1 / 2}$ should be independent of intensity. The constant $\Phi$ is derivable from the quantum yield or the radiation $G$-value for radical formation, and is normally almost independent of temperature.

From the comparison of $r_{0}$ and $r_{\gamma}$, the thermal and the radiation rates, a number of facts concerning the elementary reaction steps may be deduced. Thus the thermal initiation rate is given by the relation

$$
\frac{r_{0}^{2}}{\left(r_{\gamma} I^{-1 / 2}\right)^{2}}=\frac{k_{1}}{\Phi}
$$

i.e.,

$$
k_{1}=\Phi \frac{r_{0}^{2}}{\left(r_{\gamma} I^{-1 / 2}\right)^{2}}
$$

and all the activation energies can be obtained with the aid of bond dissociation energies and thermochemical information.

In the present instance, at least two complications are present: (a) the initiation process is not the same for gamma-ray and thermal initiation, and (b) the thermal rate is appreciable.

\subsection{Mechanism of Initiation and Termination}

In thermal initiation, the $\mathrm{C}-\mathrm{F}$ bond strength is great enough [27] so that only $\mathrm{C}-\mathrm{C}$ splitting need be considered. Therefore, we write $Q->2 \mathrm{R}$, where $\mathrm{R}$ stands for $\sim \mathrm{CF}_{2} \mathrm{CF}_{2} \cdot$. Radiation seems to produce radicals by two reactions

$$
\begin{aligned}
& Q \frac{\alpha I}{}>2 \mathrm{R} \\
& Q \stackrel{\beta I}{ }>\mathrm{R}_{\mathrm{II}}+\mathrm{F}
\end{aligned}
$$

where $R_{\text {II }}$ stands for the structure $m \dot{C}_{2} \mathrm{CFCF}_{2} m$ The evidence for $R_{I I}$ is old and direct [28] while that for $\mathrm{R}$ depends upon subtractions and upon identification of an oxygen reaction product $m \mathrm{CF}_{2} \mathrm{CF}_{2} \mathrm{O}$. $[29,30]$. Separation of the pairs $R$, generated thermally or by process $\alpha$, may be strongly hindered by cage effects, whereas in process $\beta$ separation of $\mathrm{F}$ from $R_{\text {II }}$ could be much easier. Thus, although the bond scissions in the radiation processes $\alpha$ and $\beta$ may be temperature independent, both the separation of radicals and the recombination reactions can be diffusion limited and thus in principle temperature dependent. For a diffusion-limited combination $A+B$. Smoluchowski [31] has shown that the secondorder rate constant is proportional to $\frac{1}{2}\left(D_{A}+D_{B}\right)$, i.e., to the sum of diffusion constants. Since $\mathrm{F}$ is of small volume (cf. Ne, N) and highly mobile, not only the separation efficiency of $\mathrm{F}$ but the combination rate of $\mathrm{F}$ with large radicals will be very large, $\left(\propto \frac{1}{2} D_{F}\right)$, while that for $\mathbf{R}+\mathbf{R}$ will be much smaller. There is thus no necessary equivalence between the thermal and radiation processes, in either initiation or termination, and complete temperature independence of radiation initiation is doubtful. In special circumstances both the equivalence of species and the temperature independence of radiation initiation can be valid.

Two contributing circumstances can be noted. For termination, Siegle, Muus, Lin, and Larson [6] have postulated the reaction $\mathrm{R}+\mathrm{R} k_{i_{a}} \rightarrow \mathrm{S}+\mathrm{U}$ where $\mathrm{S}$ is a saturated molecule and $\mathrm{U}$ an olefinic molecule of polymer. The radical $R_{I I}$ should also decompose at a rate which is comparable with propagation

$$
\mathrm{R}_{\mathrm{II}} \longrightarrow \mathrm{U}+\mathrm{R}
$$

$m \mathrm{CF}_{2} \mathrm{CF}_{2} \dot{\mathrm{CFCF}}_{2} \mathrm{CF}_{2} \mathrm{CF}_{2} m \longrightarrow \sim \mathrm{CF}_{2} \mathrm{CF}_{2} \mathrm{CF}=\mathrm{CF}_{2}$ $+\cdot \mathrm{CF}_{2} \mathrm{CF}_{2} \mathrm{~m}$, and is therefore rapid if there is a chain process at all. Therefore, the decomposition of $R_{I I}$ can produce as many olefinic groups as initiation process $\beta$ produces $\mathrm{F}$ atoms. If the termination of Siegle et al., occurs to an appreciable extent, olefinic groups will accumulate more rapidly than $\mathrm{F}$ atoms. It is likely that the addition of $\mathrm{F}$ to a double bond occurs with near zero activation energy (cf cases involving $\mathrm{Cl}$ [32] and at a rate roughly comparable to combination. Ultimately the large number of olefinic groups $\mathrm{U}$ will compete successfully with all radicals to consume nearly all $\mathrm{F}$ and produce further radicals $\mathrm{R}$ almost quantitatively. These processes with initiation $\beta$, in the presence of olefins, can produce $2 \mathrm{R}$, not in a cage, and almost no $F$. Other processes which compete similarly with $\mathrm{R}+\mathrm{F} \longrightarrow \mathrm{S}$ may be $\mathrm{F}+m \mathrm{CF}_{2}-\mathrm{CF}_{2}$ in $\longrightarrow m \mathrm{CF}_{3}+\cdot \mathrm{CF}_{2} \quad$ [33]; $\mathrm{F}$ $+\mathrm{CF}_{2}=\mathrm{CF}_{2} \longrightarrow \mathrm{CF}_{3} \mathrm{CF}_{2} \cdot$; and $\mathrm{F}$ (polymer melt) $\longrightarrow \mathrm{F}$ (vapor). The combination $\mathrm{F}+\mathrm{F}$ can be neglected, because of the low bond energy of $F_{2}$, 37 kcal [27], favoring dissociation at high temperature and low total concentration, and the low or zero activation energy for numerous reactions with $F_{\text {, }}$. If termination is by combination exclusively, but $R_{\Pi}$ decomposition is complete, more complex quadratic relations prevail among the several concentrations. Including the thermal rate of initiation $h_{1}(Q)$ and denoting the rates of processes $\alpha$ and $\beta$ by $\alpha(Q) I$ and $\beta(Q) I$, it is probably safe to assert the inequality

$$
\frac{\left[k_{1}+\alpha I\right][Q]}{k_{4}}<[\mathrm{R}]^{2}<\frac{\left[k_{1}+(\alpha+\beta) I\right][Q]}{k_{4}} .
$$

To the extent that $\mathrm{F}$ atom reactions occur they may reduce the pair correlation, cage effect, and temperature dependence involved in the coefficient $\alpha$.

\subsection{Radiation Initiation Rate}

Experimentally, the constant $G$-value of 3.0 for chlorine absorption suggests that in the temperature range 325 to $380{ }^{\circ} \mathrm{C}$ some sort of initiation process is temperature-independent. 
This experimental $G$-value refers to some unknown composite of the reactions:

$$
\begin{gathered}
Q \longrightarrow>2 m \mathrm{CF}_{2} \mathrm{CF}_{2} \cdot \\
Q->m \mathrm{CF}_{2} \mathrm{CFCF}_{2} m+\mathrm{F} . \\
m \mathrm{CF}_{2} \dot{\mathrm{CFCF}} m->m \mathrm{CF}=\mathrm{CF}_{2}+\cdot \mathrm{CF}_{2} m \\
m \sim \mathrm{CF}_{2} \mathrm{CF}_{2} \cdot+\mathrm{Cl}_{2} \longrightarrow \mathrm{CF}_{2} \mathrm{CF}_{2} \mathrm{Cl}+\mathrm{Cl} \\
m \mathrm{CF}_{2} \dot{\mathrm{CFCF}}_{2} m+\mathrm{Cl}_{2} \longrightarrow m \mathrm{CF}_{2} \mathrm{CFClCF}_{2} m+\mathrm{Cl} \\
m \sim \mathrm{CF}=\mathrm{CF}_{2}+\mathrm{Cl}_{2} \longrightarrow \mathrm{CFClCF}_{2} \mathrm{Cl}
\end{gathered}
$$

Losses from scission of $\mathrm{C}-\mathrm{Cl}$ bonds were presumably reversed by the excess chlorine present. An increased rate of scission at sites adjacent to $\mathrm{C}-\mathrm{Cl}$ bonds could have raised the overall scission rate in the sample, but the published rates of pyrolysis of polychlorotrifluoroethylene [34, 35] suggest that this increase would be moderate for the temperatures and times used. At the low $\mathrm{Cl}_{2}$ concentrations soluble in polytetrafluoroethylene at 300 to $400{ }^{\circ} \mathrm{C}$, the uptake of Cl must be a measure only of radicals which have escaped the primary cage. Propagation reactions should not interfere with the measurement unless chains are completely consumed; the only requirement is that reaction with $\mathrm{Cl}_{2}$ shall compete successfully with termination.

If radicals $\mathrm{R}_{\mathrm{II}}$, w $\mathrm{CF}_{2} \dot{\mathrm{CFCF}}_{2}$ m do not decompose to $\mathrm{R}$, then $G(\mathrm{Cl})$ measures $[2 \alpha+\beta][Q]$ in the notation used earlier. If they decompose quantitatively according to

$$
\begin{gathered}
\mathrm{R}_{\mathrm{II}} \longrightarrow \mathrm{R}+\mathrm{U} \\
m \mathrm{CF}_{2} \mathrm{CFCF}_{2} m \longrightarrow \sim \mathrm{CF}=\mathrm{CF}_{2}+\cdot \mathrm{CF}_{2} m
\end{gathered}
$$

and the products combine with chlorine to yield $m \mathrm{CFClCF}_{2} \mathrm{Cl}+\mathrm{ClCF}_{2}$ w , then $G(\mathrm{Cl})$ measures $[2 \alpha$ $+3 \beta][Q]$.

Other estimates of the $G$-value for radical formation in polytetrafluoroethylene, principally at room temperature, vary between 0.2 and 10 [14, 15, 36].

With reservations, the radiation initiation rate will be consolidated as $\Phi \frac{\rho}{m} I$ and it will be considered tentatively as temperature-independent and equal to the experimental chlorine absorption,

i.e., $\quad \frac{d \mathrm{Cl}}{d t}=2 \Phi \frac{\rho}{m} I$.

\subsection{Reduction of Experimental Data for Mixed Thermal and Radiolytic Initiation}

The data of figures 2 to 4 and table 1 are differences $r-r_{0}$ of the actual rate $r$ and the thermal rate $r_{0}$.
The composite initiation rate is represented by

$$
k_{1} \sum n Q_{n}+\Phi I \sum n Q_{n} .
$$

The total decomposition rate is

$$
\left.r=\frac{k_{2}\left(k_{1}+\Phi I\right)^{1 / 2}}{k_{4} \rho}\right]^{1 / 2}
$$

therefore,

$$
r-r_{0}=r_{0}\left(1+\frac{\Phi}{k_{1}} I\right)^{1 / 2}-r_{0}
$$

The relation between the photo increment $r-r_{0}$ and $I^{1 / 2}$ describes a hyperbola which has an asymptote

$$
r-r_{0}=r_{0}\left(\frac{\Phi}{k_{1}}\right)^{1 / 2} I^{1 / 2}-r_{0}
$$

The asymptote has the slope $r_{0}\left(\frac{\Phi}{k_{1}}\right)^{1 / 2}$ and intercepts at $I^{1 / 2}=\left(\frac{k_{1}}{\Phi}\right)^{1 / 2}$ and $\left(r-r_{0}\right)=-r_{0} . \quad$ Thus both the thermal rate and the ideal radiation rate parameter, eq (6) $r_{\gamma} I^{-1 / 2}=r_{0}\left(\frac{\Phi}{k_{1}}\right)^{1 / 2}$ can be isolated. In figure 4 a reasonable correspondence to the hyperbola

$$
\frac{\left(r-r_{0}+10.37 \times 10^{-7}\right)^{2}}{\left(10.37 \times 10^{-7}\right)^{2}}-\frac{\left(I^{1 / 2}\right)^{2}}{(0.792)^{2}}=1
$$

is seen.

If the hyperbola of figure 4 does not include numerous points at high $I^{1 / 2}$, determination of the asymptote is unsatisfactory, and moreover the form is not well distinguished from a parabola. Since the initiation rates are to the half power in the rate expression it also follows that $r \gamma$ the pure $\gamma$-ray initiation fractional rate of monomer volatilization is related to the total and thermal rates by the expression

$$
r_{\bar{\gamma}}^{2}=r^{2}-r_{0}^{2}
$$

Using eqs (5) and (10)

$$
\begin{aligned}
r_{\gamma}^{2} & =\frac{k_{2}^{2}}{k_{4}} \frac{m}{\rho}\left(k_{1}+\Phi I\right)-\frac{k_{2}^{2}}{k_{4}} \frac{m}{\rho} k_{1} \\
& =\left[\frac{k_{2}^{2} m}{k_{4} \rho}\right](\Phi I) .
\end{aligned}
$$

Factoring the right side of eq (12) permits the formulation

$$
\begin{aligned}
& r-r_{0}=r_{\gamma}^{2} /\left(r+r_{0}\right) \\
& r+r_{0}=r_{\check{\gamma}}^{2} /\left(r-r_{0}\right)
\end{aligned}
$$




$$
r-r_{0}=-2 r_{0}+\frac{r_{\bar{\gamma}}^{2}}{\left(r-r_{0}\right)}
$$

Rearranging and inserting the expression (eq (13)) for $r_{\bar{\gamma}}^{2}$ we obtain

$$
r-r_{0}=-2 r_{0}+\frac{k_{2}^{2}}{k_{4}} \frac{m}{\rho} \frac{\Phi I}{\left(r-r_{0}\right)}
$$

If $r-r_{0}$ is plotted against $\left(\frac{I}{r-r_{0}}\right)$, a straight line is obtained. The ideal radiation rate parameter $r_{\gamma} I^{-1 / 2}$ $=r_{0}\left(\frac{\Phi}{k_{1}}\right)^{1 / 2}$ is given by the square root of the slope, and the thermal rate $r_{0}$ by one-half the negative intercept. The difficulty with this type of plot is that at low $r-r_{0}$ the error in the abscissa $I / r-r_{0}$ is very large. Within the large error figure 5 appears to constitute the required line. The value of the negative intercept is somewhat uncertain because of the long extrapolation: therefore, $r_{0}$ is not accurately determined. An algebraically equivalent value of $r_{0}$ can also be obtained as half the product of the slope and the intercept on the $\left(I / r-r_{0}\right)$ axis.

Plots similar to figure 5 were made for various temperatures and film thicknesses, utilizing the data of figure 2. They suggest a trend to upward curvature, difficult to establish because of the few points and large associated errors.

If the radiation process involves radical pairs which remain correlated throughout their lifetimes, $r_{\gamma}$ and $r-r_{0}$ should be linear in $I$. Figure 3 shows that $r-r_{0}$ is not. Likewise figure 4 should be a parabola,

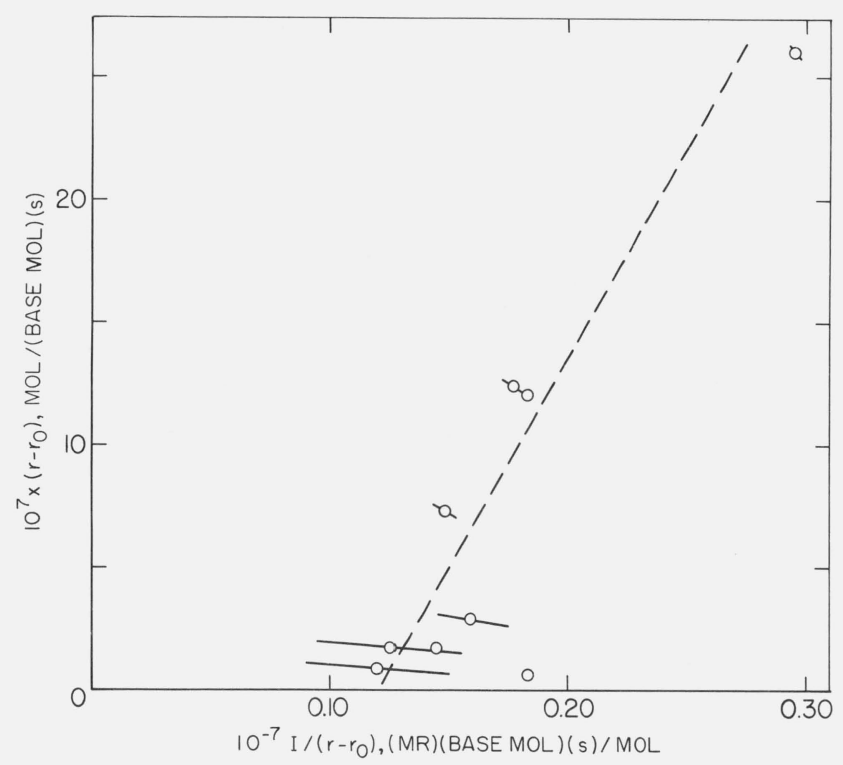

FigURE 5. Photo increment of rate of volatilization of polytetrafluoroethylene $\left(\mathrm{r}-\mathrm{r}_{0}\right)$ plotted as a function of $\mathrm{I} /\left(\mathrm{r}-\mathrm{r}_{0}\right)$, see eq (15). Corrected temperature $429.5^{\circ} \mathrm{C}$. which is more difficult to disprove, and figure 5 should be a vertical straight line. The possibility of some linear component, either from correlated pairs or molecular processes, is difficult to investigate. If the contributions are independent and the rate can be represented as

$$
r=r_{0}\left\{(1+a I)^{1 / 2}+b I\right\}
$$

where $a=\Phi / k_{1}$ it is possible to develop $r-r_{0}$ and such ratios as $\left(r-r_{0}\right) / I,\left(r-r_{0}\right) I^{-1 / 2}$ as series in $I$ or $I^{1 / 2}$, for low and high values of $a I$. In particular, a plot of $\left(r-r_{0}\right) I^{-1 / 2}$ versus $I^{1 / 2}$ has a limitirg slope $r_{0} b$ and a high dose asymptote with an intercept on the $\mathrm{Y}$-axis equal to $r_{0} a^{1 / 2}$. The data of figure 4 , treated in this fashion, did not indicate a large linear component.

The rate data for film $0.0006 \mathrm{~cm}$ thick (table 2) were anomalous and corresponded to linear variation with dose rate.

The radiation rate constant $r_{\gamma} I^{-1 / 2}$ was evaluated for the $0.0025-\mathrm{cm}$ film by two methods-from the square root of slope of plots like figure 5 , and from the highest available two points on plots like figure 4 . These results are assembled in table 7 . For $0.0025 \mathrm{~cm}$ film, these data fit the equations

$$
\begin{gathered}
r_{\gamma} I^{-1 / 2}=6.24 \exp (-21,200 / R T) \mathrm{s}^{-1} \mathrm{MR}^{-1 / 2} \mathrm{~h}^{1 / 2} \\
\quad \text { (slopes of fig. } 5 \text { plots, first line of table } 7) \\
r_{\gamma} I^{-1 / 2}=0.28 \exp (-16,900 / R T) \mathrm{s}^{-1} \mathrm{MR}^{-1 / 2} \mathrm{~h}^{1 / 2}
\end{gathered}
$$

\begin{tabular}{|c|c|c|c|c|c|c|c|}
\hline \multirow{4}{*}{$\begin{array}{l}\text { Temperature, }{ }^{\circ} \mathrm{C}^{\text {a }} \\
10^{7} r_{\gamma} I^{-1 / 2}, \\
\mathrm{~s}^{-1} \mathrm{MR}^{-1 / 2} \mathrm{~h}^{1 / 2 \mathrm{~b}} \\
10^{7} r_{\gamma} I^{-1 / 2} \\
\mathrm{~s}^{-1} \mathrm{MR}^{-1 / 2} \mathrm{~h}^{1 / 2 \mathrm{c}}\end{array}$} & \multicolumn{7}{|c|}{ Thickness, $0.0025 \mathrm{~cm}$} \\
\hline & 403.2 & 420.5 & 429.5 & $429.5^{d}$ & 443.7 & 453.1 & 468.1 \\
\hline & 8.1 & 11.2 & 13.6 & 13.0 & 19.0 & 24.0 & 43.3 \\
\hline & 8.8 & 12.2 & 14.6 & 10.7 & 17.0 & 20.3 & 35.6 \\
\hline
\end{tabular}

(highest two points of fig. 4 , plots, second line of table 7)

TABLE 7. Pure radiation rate constants for decomposition of polytetrafluoroethylene

a Corrected, see "Experimental Procedure."

${ }^{b}$ From square root of slope, as in figure 5.

c From two points at high dose rate, as in figure 4.

${ }^{a}$ Data from figures 4 and 5: all others interpolated from figure 2.

\subsection{Thermal Initiation}

The rate of thermal initiation may be computed if the description outlined in eqs (6), (12), and (17) or (18) is valid. By eq (8)

$$
k_{1}=\Phi r_{0}^{2}\left(r_{\gamma} I^{-1 / 2}\right)^{-2}
$$

The rate parameter $\Phi$ for radiation initiation is estimated from the polymer density, the polymer segment molecular weight, and the experimental $G$-value for chlorine absorption. The refined representation de- 
veloped by Siegle, Muus, Lin, and Larsen [6] can be rewritten with little loss of accuracy

$$
\frac{\rho}{m} 10^{3}=5.25 \exp (1393 / R T) \mathrm{mol} / \text { liter } 750>T^{\circ} \mathrm{K}>650 .
$$

For present purposes the value at $400{ }^{\circ} \mathrm{C}$ will be used, neglecting temperature variation, viz,

$$
\frac{\rho}{m} 10^{3}=14.38 \mathrm{~mol} / 1 .
$$

From the experimental $G(\mathrm{Cl})=3.0$, and the estimated [22] relation for polytetrafluoroethylene, $1 \mathrm{MR}=0.526$ $\times 10^{20} \mathrm{eV} / \mathrm{g}$ the value of $\Phi$ becomes

$$
\Phi=3.64 \times 10^{-8} \mathrm{~s}^{-1} \mathrm{MR}^{-1} \mathrm{hr} .
$$

By combining eqs (17) and (19) with Madorsky's [7] thermal rate,

$$
r_{0}=4.7 \times 10^{18} \exp \{-80,500 / R T\} \mathrm{s}^{-1}
$$

the resulting thermal initiation rate is,

$$
k_{1}=2.07 \times 10^{28} \exp \{-118,600 / R T\} \mathrm{s}^{-1} .
$$

A similar estimate utilizing eq (18) in place of eq (17) yields

$$
h_{1}=1.0 \times 10^{30} \exp \{-127,200 / R T\} \mathrm{s}^{-1} .
$$

Substitution of the thermal rate equation of Siegle, Muus, Lin, and Larsen [6] will yield nearly the same results. Both the activation energy and the preexponential factor are remarkably high, the preexponential factor being outside the range of usual experience.

\subsection{Propagation}

Activation energies of other steps can be computed from eqs (5), (17) or (18), (19) or (20), and the known bond dissociation energy [27] and equilibrium-pressure relationships [6]

$$
\begin{aligned}
& E_{0}=E_{2}+\frac{1}{2} E_{1}-\frac{1}{2} E_{4} \\
& E_{\gamma}=E_{2}-\frac{1}{2} E_{4} .
\end{aligned}
$$

From Bryant's C-C bond dissociation energy [27]

$$
\begin{gathered}
D_{\mathrm{C}-\mathrm{C}}=E_{1}-E_{4}=81.5 \mathrm{kcal} \\
E_{2}=E_{0}-\frac{1}{2} D_{\mathrm{C}-\mathrm{C}}=80.5-40.75 \text {, or } 39.75 \mathrm{kcal},
\end{gathered}
$$

independent of the present radiation results.

$$
\begin{aligned}
E_{4} & =2\left\{E_{0}-\frac{1}{2} D_{\mathrm{C}-\mathrm{C}}-E_{\gamma}\right\} \\
& =2\{80.5-40.75-21.2\} \\
& =37.10 \mathrm{kcal},
\end{aligned}
$$

where $E_{\gamma}=21.2 \mathrm{kcal}$ is derived from eq (17). Utilizing eq (18), the corresponding $E_{4}$ is $45.70 \mathrm{kcal}$. The value of $E_{2}=39.75 \mathrm{kcal}$ is in agreement with the equilibrium pressure relation [6] and heat of polymerization [27] and a reasonable allowance for the activation energy $E_{-2}$ of the reverse propagation of 0 to 7 kcal.

$$
\begin{aligned}
E_{2} & =H_{p}+E_{-2} \\
& =37.57+(0 \text { to } 7) \mathrm{kcal} .
\end{aligned}
$$

\subsection{Termination}

The value of $E_{4}=37.10 \mathrm{kcal}$ is in qualitative agreement with the concept that termination is diffusioncontrolled and limited by the high melt viscosity. Melt viscosity measurements [37] have been variously interpreted to indicate that the activation energy for viscous flow is $36 \mathrm{kcal}$ [37] or else [38] that below $365{ }^{\circ} \mathrm{C}$ it is about $25 \mathrm{kcal}$, and above this temperature it is $52 \mathrm{kcal}$, possibly with a chain-scission mechanism. It remains uncertain whether the apparent change near 365 or $380{ }^{\circ} \mathrm{C}$ is physical or chemical in nature, since a permanent degradation above $380{ }^{\circ} \mathrm{C}$ affects the measurements $[39,40]$.

More directly, the disappearance of radicals in irradiated polytetrafluoroethylene at temperatures up to $220{ }^{\circ} \mathrm{C}[41]$ appears to fit second-order rate expressions with relatively high activation energies

$k=6 \times 10^{13} \exp \{-30,000 \pm 3,000 / R T\}$ liter $/ \mathrm{mol} \cdot \mathrm{sec}$ (amorphous phase, $46 \%$ crystalline sample)

$k=6 \times 10^{17} \exp \{-40,000 \pm 4,000 / R T\}$ liter $/ \mathrm{mol} \cdot \mathrm{sec}$ (crystalline phase, $46 \%$ crystalline sample)

$k=6 \times 10^{26} \exp \{-65,000 \pm 5,000 / R T\}$ liter $/ \mathrm{mol} \cdot \mathrm{sec}$ (crystalline phase, $74 \%$ crystalline sample). (24)

Although the radical species is presumably m $\mathrm{CF}_{2} \mathrm{CFCF}_{2}$ w rather than $\mathrm{CF}_{2} \cdot$, the barriers to diffusion and recombination should be similar, especially in the amorphous phase.

By assuming one of these equations as a description of $2 k_{4}$ a rough estimate of $k_{2}$ can be obtained by way of eq (8), which implies

$$
k_{2}=\left(r_{\gamma} I^{-1 / 2}\right)\left[\frac{\rho}{m} 10^{3}\right]^{1 / 2} \Phi^{-1 / 2} k_{4}^{1 / 2} .
$$


Substitution of

$$
\begin{aligned}
& r_{\gamma} I^{-1 / 2}=6.24 \exp \{-21,200 / R T\} \\
& 2 k_{4}=6 \times 10^{13} \exp \{-30,000 / R T\}
\end{aligned}
$$

and $\left[\frac{\rho}{m} 10^{3}\right]=14.38,2 \Phi=7.29 \times 10^{-8}$, as previously used, gives

$$
k_{2}=7 \times 10^{11} \exp \{-36,200 / R T\} \sec ^{-1}
$$

which is close to the a priori estimate of Siegle, Muus, Lin, and Larsen [6]

$$
k_{2}=10^{13} \exp \{-36,800 / R T\} .
$$

Comparisons involving the depolymerization equilibrium [6] and the measured propagation rate in polymerization [11] would require knowledge of monomer solubility in the polymer melt.

\subsection{Kinetic Chain Length}

The kinetic chain length, $Y$, propagations/initiations is given by

$$
Y=\frac{k_{2} R}{2\left(k_{1} \sum n Q_{n}+\Phi \sum n Q_{n} I\right)}=\frac{r}{2\left(k_{1}+\Phi I\right)} .
$$

Table 8 lists a few values of $Y$ computed from $r_{0}$ (eq (1)), $r-r_{0}$ (fig. 2 with corrected temperatures), $k_{1}(\mathrm{eq}(20))$ and $\Phi(\mathrm{eq}(19))$. Thermal kinetic chain length at high temperature are much less than the estimates of Siegle et al. [6], e.g., 13 instead of 720 at $480{ }^{\circ} \mathrm{C}$. Approximate equations for the thermal kinetic chain length $Y_{0}$ and the fictitious radiation chain length neglecting thermal initiation $Y_{\gamma}$ are,

$$
\begin{aligned}
& \log _{10} Y_{0}=-9.958+8320 / T \\
& \log _{10} Y_{\gamma}=7.932-4640 / T-\frac{1}{2} \log _{10} I .
\end{aligned}
$$

In all the radiation experiments, the kinetic chain length is small. At low temperatures the chain length

\begin{tabular}{|c|c|c|c|c|c|}
\hline Temperature, ${ }^{\circ} \mathrm{C}$. & 496 & 480 & 468 & 417 & 394 \\
\hline$Y, 0 \mathrm{MR} / \mathrm{h}$, thermal. & 8 & 13 & 18 & 132 & 350 \\
\hline$Y, 0.22 \cdot \mathrm{MR} / \mathrm{h} \ldots \ldots \ldots$ & ..... & 13 & 20 & 19 & 10 \\
\hline$Y, 7.66 \mathrm{MR} / \mathrm{h} \ldots$ & $\ldots \ldots$ & 13 & 16 & 4 & 3 \\
\hline
\end{tabular}
can be great only at extremely low dose rates, involving immeasurably low decomposition rates, while at high temperatures it is small because of extensive thermal initiation.

TABLE 8. Kinetic chain lengths for polytetrafluoroethylene decomposition

\subsection{Molecular Weight as a Function of Conversion}

The molecular weight changes given by these authors then imply not that the chain length is long, but that termination occurs almost exclusively by combination. To show this, let $Q(t)=$ the total moles of polymer molecules in $W(t) \mathrm{g}$ of sample. $\bar{M}_{n}(t)=m \bar{P}(t)=$ the number average molecular weight, where $m$ is the monomer molecular weight and $\bar{P}(t)$ is the number average degree of polymerization. The sample volume is given by $V(t)=W(t) / \rho$ : the conversion to volatiles by $C=1-W(t) / W(0)$.

The rate constants and kinetic parameters are $k_{1}, k_{2}$, $k_{3}, k_{4}, k_{4 a}, r$, and $Y$, as used previously. Radical concentration, $\mathrm{mol} / \mathrm{cm}^{3}$, is denoted by $[R]$, and $r=$ fractional weight loss rate, $\mathrm{s}^{-1}, Y=$ kinetic chain length, $k_{i 2}[R] / k_{40}[R]^{2}$. Also let $k_{40}=k_{4}+k_{4 a}$, and $\sigma=\frac{k_{3}[R] \rho / m}{2 k_{40}[R]^{2}}$, the chain transfer constant.

A constant steady-state radical concentration is maintained as in eq (4):

$$
[R]^{2}=\frac{k_{1}}{k_{40}} \frac{\rho}{m} .
$$

By virtue of the constant fractional weight loss rate $r$

$$
\begin{aligned}
V(t) & =\frac{W(t)}{\rho}=\frac{W(0)}{\rho} e^{-r t} \\
& =\frac{W(0)}{\rho} e^{-2 k_{1} Y t} .
\end{aligned}
$$

The total number of polymer molecules is left unchanged by initiation and combination, and increased by one by disproportionation and by chain transfer. Therefore,

$$
Q(t)=Q(0)+\int_{0}^{t}\left(k_{4 a}[R]^{2}+k_{3}[R] \frac{\rho}{m}\right) V(t) d t .
$$

Noting that

$$
\begin{aligned}
k_{4 a}[R]^{2}+k_{3}[R] \frac{\rho}{m} & =k_{40}[R]^{2}\left(\frac{k_{4 a}}{k_{40}}+\frac{k_{3}[R] \frac{\rho}{m}}{k_{40}[R]^{2}}\right) \\
& =\frac{k_{1} \rho}{m}\left(\frac{k_{4 a}}{k_{40}}+\sigma\right), \\
Q(t)-Q(0) & =\frac{k_{1} \rho}{m}\left(\frac{k_{4 a}}{k_{40}}+\sigma\right) \int_{0}^{t} \frac{W(0)}{\rho} e^{-2 k_{1} Y t} d t \\
& =\frac{k_{1} W(0)}{m}\left(\frac{k_{4 a}}{k_{40}}+\sigma\right) \frac{1}{2 k_{1} Y}\left(1-e^{-2 k_{1} Y t}\right) \\
& =\left(\frac{k_{4 a}}{k_{40}}+\sigma\right) \frac{W(0) C}{2 m Y} .
\end{aligned}
$$


Since

$$
\begin{aligned}
& Q(t)=\frac{W(t)}{\bar{M}_{n}(t)}=\frac{W(0)\{1-C(t)\}}{m \bar{P}(t)}, \\
& \frac{1-C}{\bar{P}(t)}-\frac{1}{\bar{P}(0)}=\left(\frac{k_{4 a}}{k_{40}}+\sigma\right) \frac{C}{2 Y} .
\end{aligned}
$$

A plot of $\frac{1-C}{\bar{P}(t)}$ versus $C$ should be linear, with a slope $\frac{1}{2 Y}\left(\frac{k_{4 a}}{k_{40}}+\sigma\right)$. From the data of Siegle et al. [6], one estimates for the slope the value $6.4 \times 10^{-4}$. The equation utilized previously [6] is somewhat unnecessarily imprecise and was derived assuming all termination to be by disproportionation. By substituting the chain length $Y=13$, it can be concluded, with reservations due to the large experimental error, that neither $k_{4 a} / k_{40}$ nor $\sigma$ is much larger than $3 \times 10^{-3}$. Alternatively, the molecular weight changes cited could be a consequence of reaction with impurities. If each molecule of impurity reacts to generate a chain break, the number of moles of impurities that have reacted at 16 percent conversion is given by

$$
\begin{aligned}
Q(0.16) & =Q(0)+x \\
x & =\frac{W(0)(1-0.16)}{1.2 \times 10^{6}}-\frac{W(0)}{9 \times 10^{6}} .
\end{aligned}
$$

Thus, reaction of impurities to the extent $\frac{x m}{W_{0}}=5.9$ $10^{-5}$ of the number of moles of chain segments could also account for the observed molecular weight decrease at 16 percent conversion. Half of this reaction could have taken place before 4 percent conversion, as judged by the earliest experimental molecular weight. The present picture of low kinetic chain length and little, if any, disproportionation is consistent with many other observations in the literature, viz, the failure to observe disproportionation products in experiments with perfluoroalkyl radicals [43], and inhibition studies in which the polymer was decomposed in the presence of various gases and fluorine atoms [33]. The decomposition of polytetrafluoroethylene if carried out in the presence of a perfect inhibitor, i.e., a chemical species that reacted only with the radicals formed by random thermal initiation to produce a stable molecule, should exhibit a net random decomposition type of $\frac{d C}{d t}$ versus $C$ curve [4], and the rate constant for the random decomposition should be identical to the thermal initiation constant for the thermal volatilization reaction studied here. Random decomposition can be shown to give a behavior characterized by a maximum in $d C / d t$ at 26 percent conversion and in our case related to the rate constant by the expression

$$
\left(\frac{d C}{d t}\right)_{\text {max }} \doteq k_{1} L / e
$$

where $e$ is the base for the natural logarithm and $L$ the critical size for evaporation [4]. Hydrogen appears to be the best inhibitor studied [33] showing a maximum in $d C / d t$, albeit not quite at $C=0.26$. Applying the above expression to the maxima of the earlier data [33] one obtains

$$
k_{1}=10^{30.4} e^{-118,000 / R T}
$$

which is in very good agreement with the initiation constant deduced from the comparison of the thermal and $\gamma$-ray rates.

\subsection{Diffusion Effect on Initiation and Termination}

The large activation energy and pre-exponential factor for thermal initiation, $A_{1}$ and $E_{1}$, differ considerably from previous ad hoc speculations. The experimental values reported here are sensitive to experimental errors, as illustrated by the differences between eqs (20) and (21), and their validity depends upon the realization of the rather stringent conditions already discussed in connection with the initiation and termination in the presence of radiation. The high $E_{1}$ can be attributed to the need for diffusion of radicals out of the primary cage, comparable to the highenergy diffusion process governing $E_{4}$. The large preexponential factor, $4 \times 10^{28}$, is difficult to explain on the basis of diffusion out of the cage. For small molecules, the analysis of Rabinowitch [44], especially his eqs (8) and (3), leads to a fraction $f$ escaping recombination

$$
f=\frac{\frac{4 D_{0} e^{-E_{D} / R T}}{a^{2} \gamma}}{\frac{4 D_{0} e^{-E_{D} / R T}}{a^{2} \gamma}+\nu e \frac{\Delta S^{\neq}}{e^{-E_{C} / R T}}} .
$$

Here $D_{0} e^{-E_{D}{ }^{\prime} / R T}$ is the diffusion coefficient in obvious notation, $a$ is the distance between lattice points in $\mathrm{cm}, \gamma$ is a ratio of total to ineffective lattice displacements, $\nu$ is a frequency close to the limiting Debye frequency $\cong 5 \times 10^{12} \mathrm{sec}^{-1}$ and $E_{C}$ is the activation energy for combination within the cage, taken as zero. A factor $e^{\Delta \varsigma \neq / R}$ has been inserted to allow for a possible entropy of activation for cage recombination.

If the fraction $f$ is to be of Arrhenius form with the requisite preexponential factor,

$$
f \approx \frac{10^{28}}{10^{14}} e^{-E_{D} / R T}
$$


this requires

$$
\frac{4 D_{0} e^{-E_{D} / R T}}{a^{2} \gamma} \ll \nu e^{\Delta S \neq / R}
$$

and

$$
\frac{4 D_{0}}{a^{2} \gamma \nu e^{\Delta S \neq R}} \approx 10^{14}
$$

These conditions can be met only if $e^{-E_{D} / R T} \ll 10^{-14}$, which at $650{ }^{\circ} \mathrm{K}$ requires the excessively high $E_{D}$ $>83 \mathrm{kcal}$. The second condition alone is impossible unless either $D_{0}$ is much greater than the ideal smallmolecule value $D_{0}=\frac{1}{2} a^{2} n \nu$ given by Rabinowitch, or $\Delta S{ }^{*}$ is large and negative.

Alternatively, the large $A_{1}$ could be explained by supposing that several bonds are loosened in the transition state. According to this view, the loosening effect contributes about 40 eu to the transition state for dissociation of ethane [45] and raises the preexponential factor to $10^{17}$; in the present instance a contribution of about $80 \mathrm{eu}$ is needed.

It is also conceivable that escape from the primary cage occurs mainly when dissociation is followed by one propagation step. Essentially this idea has been used to explain the transition from low-temperature radiolysis of petroleum products to a so-called radiation thermal cracking, the rate of which is proportional to dose rate but has a high activation energy [45]. Applied to thermal decomposition of polytetrafluoroethylene, the activation energy increment would be $E_{2}$ and the effective $E_{1}$ would be $D_{C-C}+E_{2}$, which is numerically not far from the $E_{1}$ deduced here. However, arguments similar to those for cage escape would require $A_{1 C} A_{2} / A_{4 C} \approx 10^{28}$, where the subscript $C$ denotes cage reactions, and this cannot be met with "normal" preexponential factors. In general, the kinetics of these authors should not apply here, since, in polytetrafluoroethylene, decomposition to olefin, i.e., propagation, does not destroy a radical as in their system, but leaves it unchanged as a kinetic entity.

For related reasons, it is very difficult to devise kinetics of radiolysis involving "unzipping" for a kinetic chain length which is long but less than the degree of polymerization, which can result in decomposition linear in dose rate. The usual conclusion, that about half of the radical pairs escaping the primary cage will never recombine with their original partners $[47,48]$, implies that the steady-state concentration of all radicals, paired and unpaired, will be governed largely by bimolecular termination and thus go as the square root of dose rate. Perhaps a complex intermediate behavior could be observed in special situations.

\subsection{Diffusion Effect on Propagation}

The idea that the reverse propagation reaction

$$
R_{m}+M \stackrel{k_{-2}}{\underline{2}}>R_{m+1}
$$

could be a factor is suggested by the appreciable partial pressures of monomer existing in some of the present experimental work, and by the low values of the published thermodynamic equilibrium pressure [6]. The equilibrium pressures could be in error by a factor of ten. Preliminary arguments against reverse polymerization as a serious influence are

(1) At different helium flow rates, the partial pressure of monomer varied widely, but the observed rate of evolution remained approximately unchanged.

(2) The observed rates were nearly the same in 0.01 - and $0.0025-\mathrm{cm}$ sample thicknesses, despite the four-fold difference in monomer partial pressure.

(3) In the pyrolyses reported by Siegle et al. [6], the presence of excess monomer pressure, although it profoundly altered the product composition, reduced the rate of weight loss only by about 50 percent. At $380{ }^{\circ} \mathrm{C}$, when polymerization should have been highly favored by thermodynamics, it proceeded only very slowly, although its reverse had measurable velocity in independent experiments in a vacuum. It is possible that the monomer concentration was actually maintained at a low level either by thermal dimerization (not favored at too low a pressure) [49] or by transfer to monomer

$$
\mathrm{RCF}_{2} \mathrm{CF}_{2} \cdot+\mathrm{C}_{2} \mathrm{~F}_{4} \rightarrow \mathrm{RCF}=\mathrm{CF}_{2}+\mathrm{C}_{2} \mathrm{~F}_{5} .
$$

or

$$
\mathrm{RCF}_{2} \mathrm{CF}_{2} \cdot+\mathrm{C}_{2} \mathrm{~F}_{4} \longrightarrow \mathrm{RCF}_{2} \mathrm{CF}_{3}+\mathrm{C}_{2} \mathrm{~F}_{3} .
$$

which is only very slightly endothermic [27].

The problem of diffusion-limited monomer evolution in depolymerization has been treated by Cowley and Melville [1]. However, the possibility that reverse depolymerization occurs to an appreciable extent, arising from a buildup of the concentration of monomer in the bulk polymer, does not appear to have been treated explicitly.

The sample can be regarded as a slab of thickness $l \mathrm{~cm}$, with no flux of material through the bottom surface $(x=0)$ and open at the top $(x=l)$. This differs from the slab of Cowley and Melville [1] which corresponds to two such slabs assembled bottom to bottom. Monomer is generated within a volume element of $1 \mathrm{~cm}^{3}$ of the slab at a net rate

$$
\frac{d M}{d t}=k_{2}[R]-k_{-2}[R][M],
$$

where $[M]$ is monomer concentration, in units of $\mathrm{mol} / \mathrm{cm}^{3},[R]$ is radical concentration in the same units, the latter being constant throughout the slab, $t$ is in seconds, $k_{2}$ is in $\mathrm{s}^{-1}$, and $k_{-2}$ is in $\mathrm{cm}^{3} \mathrm{~mol}^{-1} \mathrm{~s}^{-1}$. Monomer at $x=l$ is in solubility equilibrium with monomer in the gas phase at a partial pressure $p$, with a Henry's Law constant $S$ : 
The differential equation governing monomer concentration in the slab is then

$$
\left(\frac{d[M]}{d t}\right)=D\left(\frac{\partial^{2}[M]}{\partial x^{2}}\right)+k_{2}[R]-k_{-2}[R][M]
$$

where $D$ is the diffusion constant, $\mathrm{cm}^{2} / \mathrm{s}$. The initial condition is $[M]=0$ everywhere and boundary conditions are

$$
\begin{gathered}
{[M]=S p \text { at } x=l} \\
\frac{[\partial M]}{\partial x}=0 \text { at } x=0 \text { (no flux). }
\end{gathered}
$$

The steady-state solution, for $\frac{d[M]}{d t}=0$ is given by the usual methods for linear differential equations with constant coefficients.

$$
[M]=\frac{k_{22}}{k_{-2}}+\left(S p-k_{2} / k_{-2}\right) \frac{\cosh \left\{x\left(\frac{k_{-2}[R]}{D}\right)^{1 / 2}\right\}}{\cosh \left\{l\left(\frac{k_{-2}[R]}{D}\right)^{1 / 2}\right\}}
$$

The rate of monomer escape per unit area or flux out of the top surface is given, in $\mathrm{mol} / \mathrm{cm}^{2} \mathrm{~s}$, by the usual condition applied at the surface $x=l$

$$
\left.\left.F=\frac{d s}{d t}\right)_{x=l}=-D \frac{\partial[M]}{\partial x}\right)_{x=l}
$$

where $s$ refers to moles of monomer passing through a $1 \mathrm{~cm}^{2}$ surface element in an imaginary plane at position $x$.

The rate per unit volume is given by $A F / V$, i.e., by $F / l$, and the rate per unit weight by $F / \rho l$, where $A$ is the surface area, $V$ the volume and $\rho$ the density. Evaluation of the derivative amd multiplication give, as the rate in moles/(base mole)(sec)

$$
\frac{D}{100 \rho l}\left(\frac{k_{22}}{k_{-2}}-S p\right)\left\{\frac{k_{-2}[R]}{D}\right\}^{1 / 2} \tanh l\left\{\frac{k_{-2}[R]}{D}\right\}^{1 / 2}
$$

Utilizing the relationship between rate constants and equilibrium constants

$$
k_{-2} / k_{2}=K_{C}=S K_{p}
$$

and the composite parameter

$$
Z=l\left(k_{-2}[R] D^{-1}\right)^{1 / 2}=l\left(k_{2}[R] D^{-1} S^{-1} K_{p}^{-1}\right)^{1 / 2}
$$

the rate in moles/(base mole)(sec) is

$$
\frac{k_{2}[R]}{100 \rho}\left\{1-\frac{p}{K_{p}}\right\} \frac{\tanh Z}{Z} .
$$

Although $p$ is related to the monomer evolution rate, gas flow rate and sample weight by an easily derived proportionally constant, the insensitivity of observed results to flow rate suggest that it is safe to neglect the term $p / K_{p}$.

For the case $p=0$, Carslaw and Jaeger [50] give a complete solution including the time-dependent behavior, which becomes identical with the equation of Cowley and Melville [7] upon proceeding to the limit of no reverse reaction.

The steady state in the limit of infinite thickness is easily derived from the general solution given above

$$
[M]=S K_{p}\left\{1-\left(1-\frac{p}{K_{p}}\right) \exp \left(-x\left(\frac{k_{i 2}[R]}{D S K_{p}}\right)^{1 / 2}\right)\right\},
$$

$$
F=\left(k_{i 2}[R] D S K_{p}\right)^{1 / 2}\left\{1-S_{p}\right\}
$$

If $p / K_{p}$ is negligible, the monomer concentration is within $e^{-2}$ of its limiting value at a depth in $\mathrm{cm}$

$$
x=2\left(\frac{k_{2}[R]}{D S K_{p}}\right)^{-1 / 2}
$$

The corresponding time-dependent surface flux is

$$
F=\left(k_{i 2}[R] D S K_{p}\right)^{1 / 2} \operatorname{erf}\left(k_{i 2}[R] S K_{p}{ }^{-1} t\right)^{1 / 2}
$$

if $p=0$. This form may possibly apply at very low temperatures and great thicknesses, if monomer production alone is measured, but does not apply in the present experiments.

In the present work, the time-dependent region is masked by holdup of vapor in the reaction furnace, and the steady-state is reached before $20 \mathrm{~min}$ and perhaps long before this time. Thus the steady-state form eq (35) applies. The solid line in figure 6 shows a logarithmic plot of the ratio, rate $/ k_{2} R$, as a function of $Z$, according to eq (35) with $p=0$. The experimental rate-differences, $r-r_{0}$, are shown on the same plot as a function of thickness at constant temperature and dose rate. A logarithmic plot of the rate $r$ versus I should have the same shape as the curve, with coordinates shifted. It is seen that there is no correspondence with the curve. The use of the correct but somewhat uncertain $r$ in place of $r-r_{0}$ would not appreciably alter the disagreement. Dose rate variations could be explored somewhat similarly if thermal initiation were negligible. The simplest explanation of the very high rate at a thickness of $0.0006 \mathrm{~cm}$ is a combination of uniform bulk rate $b$ with a high surface rate $a$. A plot of rate versus thickness would be a hyperbola, $r=b+a / l$ which appears to be the variation encountered. The surface rate $a$ could involve either the polymer-gas interface or the polymer-metal interface, as suggested by recent studies at much higher temperature [51].

It is conceivable that the observed surface rate is a result of a higher temperature in the thinner samples. 


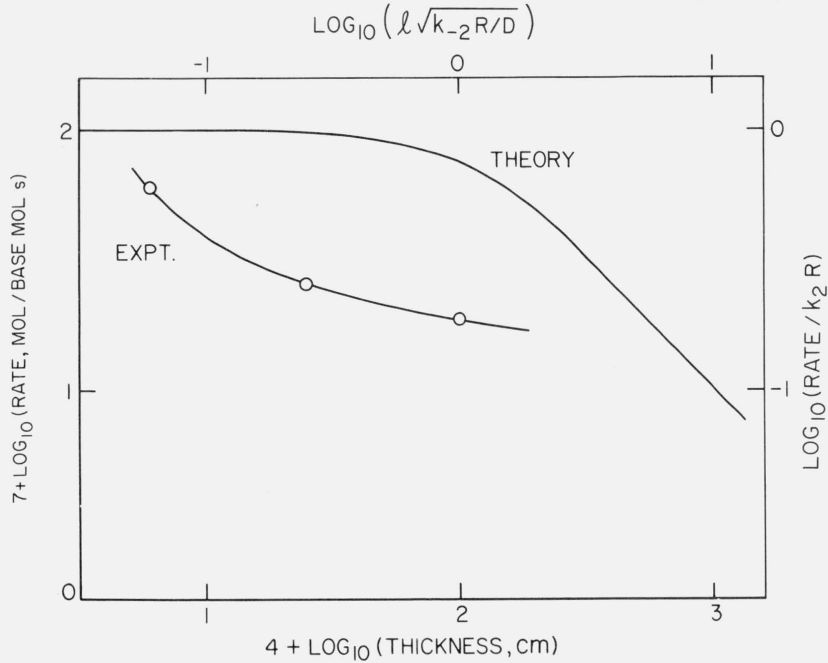

FigURE 6. Gas evolution rates as a function of sample thickness, eq (35).

Upper curve, theoretical variation of $r$ with thickness for rate limited by reverse reaction and diffusion. Lower curve experimental, $r-r_{0}$, for polytetrafluoroethylene at $429.5{ }^{\circ} \mathrm{C}$, $7.60 \mathrm{MR} / \mathrm{h}$.

Sample temperature is not easily controlled and measured with such thin films. The sample temperature is a function of many factors, heat of reaction, thermal conductivity of polymer, radiative heat transfer, heat capacity of the furnace, and others. Another reasonable mechanistic concept for the greater rate from the thin films is that the concentration of polymer radicals is greater as a result of a more rapid loss of small radicals whose only function would be in termination.

Although our rate studies indicate that diffusion and reverse reaction do not dominate the radiationinduced decomposition, it is very likely from the product compositions, table 6 , that the process is appreciably perturbed by these influences and by side reactions not present in the usual thermal decomposition in a vacuum. At a low enough temperature these influences will be major. A rough estimate of these effects can be made with the aid of eq (38), which asserts that in a semi-infinite slab the monomer concentration is $1-e^{-2}$ of the equilibrium value at a depth $2 K_{c}^{1 / 2} D^{1 / 2}\left(k_{2}[R]\right)^{-1 / 2}$.

For temperatures low enough to avoid appreciable thermal initiation, $k_{22}[R]=r_{\gamma}\left[\frac{\rho}{m}\right]$ is taken from eq (17): in $\mathrm{mol} / \mathrm{cm}^{3} \mathrm{~s}$, this is approximately

$$
9.0 \times 10^{-2} I^{1 / 2} \exp \{-21,200 / R T\} \frac{\mathrm{mol}}{\mathrm{cm}^{3} \mathrm{~s}},
$$

$D$ is estimated from the room temperature value of Goldfarb et al. [42], and an activation energy in the range 8.4 to $14.6 \mathrm{kcal}$ found for various gases in polytetrafluoroethylene [51]. Using the corrected value [42] of $D=1.2 \times 10^{-8} \mathrm{~cm}^{2} / \mathrm{s}$ at $24{ }^{\circ} \mathrm{C}$ and taking $E_{D}=$ $9,000 \mathrm{cal}$, the estimate gives

$$
D(T)=5.2 \times 10^{-2} \exp (-9,000 / R T) .
$$

The solubility could be estimated similarly from the same sources.

A likely upper limit can be found by assuming ideal solubility in polymer segments and extrapolating the vapor pressure equation [53] far beyond the critical temperature [54]. On this basis the solubility $S$ is

$S=5.2 \times 10^{-7} \exp (+3,965 / R T) \mathrm{mol} / \mathrm{cm}^{3} \mathrm{~atm}$.

Combination with the thermodynamic equilibrium pressure data [6] yields

$K_{c}=4.37 \times 10^{1} \exp \{-31,735 / R T\} \mathrm{mol} / \mathrm{cm}^{3}$

over the range 390 to $480{ }^{\circ} \mathrm{C}$. The depth for $C=K_{c}\left(1-e^{-2}\right)$ is, by substitution in eq $(38)$

$$
2.2 I^{-1 / 4} \exp \{-9,700 / R T\} \mathrm{cm} .
$$

At a temperature of $340^{\circ} \mathrm{C}$ and a dose rate of $1 \mathrm{MR} / \mathrm{h}$, this is $8 \times 10^{-4} \mathrm{~cm}$, and films of this thickness would be approaching semi-infinite behavior, with a rate of monomer evolution dependent mainly upon surface area. Under these circumstances it is not surprising that the principal products observed at the lowest temperatures are complex mixtures, arising from termination and from side reactions.

\section{Summary}

The decomposition of polytetrafluoroethylene exposed to gamma radiation at dose rates of 0.1 to 7.6 $\mathrm{MR} / \mathrm{h}$ appears to be a process with a relatively short chain length and a rate near $400{ }^{\circ} \mathrm{C}$ not many times greater than the thermal rate. The rate is essentially proportional to the square root of the dose rate and mutual termination occurs. The very low activation energy, $84 \mathrm{~kJ} / \mathrm{mol}$ for the $\gamma$-ray process indicates a very high activation energy for thermal initiation which is supported by earlier observations. It is unlikely that diffusion of the monomer through the polymer is hindered to such an extent that repolymerization is important. The deduced rate of thermal initiation has an abnormally high preexponential factor and a high activation energy, and the activation energy for termination is also high. The very short kinetic chain length and well-known independence of initial molecular weight together indicate that thermal initiation is random.

The short chain length and the previously observed molecular weight changes indicate that the termination step occurs nearly exclusively by radical combination. The observed decrease in $D P$ over that anticipated for termination exclusively by combination can be the result of very small amounts of other processes such as disproportionation, transfer or impurities. At lower temperatures but above the melting transition, the $\gamma$-ray induced decomposition has little temperature dependence and the volatile 
products are very complex and presumably the result of direct radiolysis. This complex low-temperature process is probably what was observed by Taubman and Ianova.

The authors thank Dr. C. A. Sperati and E. I. du Pont de Nemours \& Co., for the molecular weight samples and data.

\section{References}

[1] P.R.E.J. Cowley and H. W. Melville, Proc. Roy. Soc. A210, 461 (1951): A211, 320 (1952).

[2] R. Simha, L. A. Wall, and P. J. Blatz, J. Polymer Sci. 5, 615 (1950).

[3] R. Simha and L. A. Wall, J. Polymer Sci. 6, 39 (1951).

[4] R. Simha and L. A. Wall, J. Phys. Chem. 56, 707 (1952).

[5] H. B. Klevens and J. R. Platt, J. Am. Chem. Soc. 69, 3056 (1947).

[6] J. C. Siegle, L. T. Muus, Tung-Po Lin, and H. A. Larsen, J. Polymer Sci. A2, 391 (1964)

[7] S. L. Madorsky, V. E. Hart, S. Straus, and V. A. Sedlak, J. Res. NBS 51, 327 (1953) RP2461.

[8] S. L. Madorsky, J. Res. NBS 62, 219 (1959) RP2957.

[9] S. L. Madorsky and S. Straus, J. Research NBS 64A (Phys. and Chem.) No. 6, 513 (1960).

[10] S. L. Madorsky, Vacuum Microbalance Techniques, Vol. 2, p. 56. (Plenum Press, Inc., 1962.)

[11] M. I. Bro, E. R. Lovejoy, and G. R. McKay, J. Appl. Polymer Sci. 7, 2121 (1963).

[12] C. A. Sperati and H. W. Starkweather, Jr., Fortschritte der Hochpolymeren-Forschung 2, 488 (1961): ibid, 472.

[13] J. A. Wethington, Jr., in Fluorine Chemistry, ed., Vol. 5, p. 282-294. J. H. Simons (Academic Press, New York, 1964).

[14] R. E. Florin and L. A. Wall, J. Res. NBS 65A (Phys. and Chem.) No. 4, 384 (1961).

[15] R. E. Florin and L. A. Wall, SPE Trans. 3, 293 (Oct. 1963).

[16] A. B. Taubman and L. P. Ianova, All Union Conference on Radiation Chemistry, Moscow 1957, p. 287, discussion 306: tr. Consultants Bureau Inc. pp. 271, 291.

[17] E. E. Lewis and M. A. Naylor, J. Am. Chem. Soc. 69, 1968 (1947).

[18] A. Barlow, R. S. Lehrle, and J. C. Robb, Polymer 2, 27 (1961).

[19] H. Purnell, Gas Chromatography, p. 278, Table 1 (Wiley \& Sons, Inc., N. Y., 1962).

[20] H. H. Young, Jr. and L. P. Hammett, J. Am. Chem. Soc. 72, 280, eq 2 (1950).

[21] J. G. Lewis, J. V. Nehemias, D. E. Harmer and J. J. Martin, Nucleonics 12, [1], p. 40 (1954).

[22] Report of the International Commission on Radiological Units and Measurements (ICRU) 1956: NBS Handbook 62: pp. 10-17 (1956).

[22a] L. V. Spencer and F. H. Attix, Radiation Research 3, 239 (1955).

[23] Modern Plastics Encyclopedia, 1963: Union Carbide Section, "Krene, cast, plasticized". (1963).
[24] J. H. Golden, J. Polymer Sci. 45, 534 (1960).

[25] D. Cordischi, M. Lenzi, and A. Mele, Trans. Faraday Soc. 60 , 2047 (1964).

[26] F. L. Mohler, V. H. Dibeler, and R. M. Reese, J. Res. NBS 49, 343 (1952) RP2370.

[27] W. M. D. Bryant, J. Polymer Sci. 56, 277 (1962).

[28] H. N. Rexroad and W. Gordy, J. Chem. Phys. 30, 399 (1959).

[29] T. Matsugashita and K. Shinohara, J. Chem. Phys. 35, 1652 (1961).

[30] N. Tamura, J. Polymer Sci. 60, 55 (1962).

[31] M. V. Smoluchowski, Z. Physik. Chem. (Leipzig) 92, 102 (1917)

[32] E. W. R. Steacie, Atomic and Free Radical Reactions, 2d ed. ACS Monograph 125, Vol. 2 (Reinhold, New York, 1954), p. 670

[33] L. A. Wall and J. D. Michaelson, J. Res. NBS 56, 27 (1956) RP2644: J. D. Michaelson and L. A. Wall, J. Res. NBS 58 , 327 (1957) RP2765.

[34] S. L. Madorsky and S. Straus, J. Research NBS 55, 223 (1955) RP2624.

[35] L. A. Wall and S. Straus, J. Res. NBS 65A (Phys. and Chem.) No. 3, 233 (1960).

[36] A. Nishioka, K. Matsumae, M. Watanabe, M. Tajima, and M. Owaki, J. Appl. Polymer Sci. 2, 117 (1959).

[37] A. Nishioka and M. Watanabe, J. Polymer Sci. 24, 298 (1957).

[38] L. C. Case, J. Appl. Polymer Sci. 3, 254 (1960).

[39] A. V. Tobolsky, D. Katz, and A. Eisenberg, J. Polymer Sci. A 1, 483 (1963).

[40] M. Takahashi and A. V. Tobolsky, Polymer Letters 2, 129 (1964).

[41] Yu. D. Tsvetkov, Ya. C. Lebedev, and V. V. Voevodsky, Vysokomol. Soed. 3, 887 (1961).

[42] I. J. Goldfarb, R. J. McHenry, and E. C. Penski, J. Polymer Sci. 58, 1283 (1962): E. C. Penski, private communication: E. C. Penski and I. J. Goldfarb, Polymer Letters 2, 55 (1964).

[43] G. O. Pritchard, G. H. Miller, and J. R. Dacey, Can. J. Chem. 39, 1968 (1961).

[44] E. Rabinowitch, Trans. Faraday Soc. 33, 1225 (1937).

[45] A. F. Trotman-Dickenson, Free Radicals, p. 38 (Methuen, London, 1959).

[46] A. M. Brodskii, K. P. Lavrovskii, and V. B. Titov, Kinetika i Kataliz 4, 337 (1963).

[47] A. Kupperman, in The Chemical and Biological Action of Radiation, ed. M. Haissinsky (Academic Press, London, 1961), Vol. 5, p. 123

[48] R. M. Noyes, J. Am. Chem. Soc. 77, 2042 (1955).

[49] B. Atkinson and A. B. Trenwith, J. Chem. Soc. 1953, 2084 (1953).

[50] H. S. Carslaw and J. C. Jaeger, Conduction of Heat in Solids, 2d ed (Clarendon Press, Oxford, 1959), p. 404.

[51] H. H. G. Jellinek and H. Kachi, Am. Chem. Soc. Polymer Preprints 5, [2], p. 375 (Sept. 1964).

[52] W. W. Brandt and G. A. Anysas, J. Appl. Polymer Sci. 7, 1924 (1963).

[53] M. M. Renfrew and E. E. Lewis, Ind. Eng. Chem. 38, 870 (1946).

[54. S. Glasstone, Textbook of Physical Chemistry, 2d ed., p. 702 (Van Nostrand, New York, 1946).

(Paper 70A2-387) 